\title{
A New Assessment in the Simultaneous Optimization of Friction Dampers in Plane and Spatial Civil Structures
}

\author{
Sergio Pastor Ontiveros-Pérez, ${ }^{1}$ Letícia Fleck Fadel Miguel, ${ }^{1}$ \\ and Leandro Fleck Fadel Miguel ${ }^{2}$ \\ ${ }^{1}$ Department of Mechanical Engineering, Federal University of Rio Grande do Sul, Porto Alegre, RS, Brazil \\ ${ }^{2}$ Department of Civil Engineering, Federal University of Santa Catarina, Florianópolis, SC, Brazil \\ Correspondence should be addressed to Sergio Pastor Ontiveros-Pérez; sergio.ontiveros@ufrgs.br
}

Received 31 August 2017; Revised 22 November 2017; Accepted 5 December 2017; Published 31 December 2017

Academic Editor: Julius Kaplunov

Copyright (C) 2017 Sergio Pastor Ontiveros-Pérez et al. This is an open access article distributed under the Creative Commons Attribution License, which permits unrestricted use, distribution, and reproduction in any medium, provided the original work is properly cited.

\begin{abstract}
This paper presents a methodology to improve installation of friction dampers in civil structures subjected to artificial and real earthquakes using a metaheuristic optimization technique. The Firefly Algorithm is used in this work and it is linked with a computational routine based on Finite Differences Method to solve simultaneous optimization of friction dampers problem. The methodology is implemented for two kinds of structures: a 2D steel frame building and a 3D concrete frame building. The scope of this study is to reduce two different objective functions: (i) the maximum displacement at the top of a structure and (ii) maximum interstorey drift. The results showed that the methodology was able to reduce two objective functions and it can be recommended as an efficient tool to project optimal fiction dampers.
\end{abstract}

\section{Introduction}

In order to avoid structural damage due to natural hazards like earthquakes, structural engineering has presented several advances in seismic energy dissipation devices. These devices could be active or passive and their implementation depends on project investment. The active devices change their properties in function of structural response; for this reason, they are most expensive. On the other hand, passive devices are cheaper than active ones, presenting a low cost of installation and maintenance.

Because of their characteristics, passive devices stand out between energy dissipation devices increasing development of several of these devices, such as, viscoelastic dampers, metallic yield dampers, and friction dampers [1]. Additionally, an increasing number of applications of this kind of passive control systems highlight effectiveness of these devices in reducing dynamic structural response, as demonstrated in the works found in literature, for example, [2-6]. To allow an economic use of these sorts of devices, in the last decade several researches have started development of damper optimization methodologies with the aim of optimizing their parameters and best location on structure. In literature it is possible to find several papers about optimization of Tuned Mass Dampers (TMD), as, for instance, [7-13]. On the other hand, few works about optimization of friction dampers are found in literature, for example, [14-19].

The main goal of this work is to present a methodology for carrying out simultaneous optimization (friction forces and best places in structure) for a maximum number of friction dampers using a metaheuristic optimization algorithm such as Firefly Algorithm improving installation of this sort of devices in buildings located in regions with high seismic activity with the aim of carrying out a passive control of structural response. The dynamic response is obtained by a computational routine based on Finite Differences Method developed by the authors and it is linked with optimization algorithm.

The metaheuristic algorithms are more suitable to deal with dampers optimization problems because location of a friction dampers at a particular position in building is a discrete number; it is a discrete design variable, whereas 
friction forces of each damper are represented by a continuous number, that is, a continuous design variable. Thus, optimization problem presented in this work is a mixedvariable problem and such problems are usually nonconvex. According to Miguel et al. [20] metaheuristic algorithms are capable of solving such problems and some of salient characteristics of this sort of optimization techniques are as follows: (a) they do not require gradient information; (b) if metaheuristic algorithm is correctly tuned, it does not become trapped in local minima; (c) it is possible to apply in problems with discontinuous functions; (d) they provide a set of optimal solutions rather than a single one, giving to the designer a range of options to choose; (e) it is possible to use in solving mixed-variable optimization problem.

Finally, optimization of friction dampers is a relatively unexplored subject in the world, and this paper proposes a methodology for optimization of this kind of passive energy dissipation device.

\section{Optimization Problem}

Concerning civil structures located in regions with high seismic activity, engineers are usually able to suggest a suitable set of solutions to avoid structural damage. In order to avoid classical approaches based on trial and error, optimization techniques applied to energy dissipation devices have become an important tool for design engineers, avoiding high costs in project. In this way, it is possible to obtain optimal device parameters. For friction damper location problem, calculation of structure response for every possible arrangement of friction dampers mechanical parameters turns out to be a very time consuming procedure because each case requires a dynamical analysis of structure subjected to an external force such as earthquakes.

In the last years, some researchers such as Mousavi \& Ghorbani-Tanha [21] have been optimizing location of viscoelastic dampers using Genetic Algorithms (GA) for reducing structure dynamic response in terms of displacement. In this research, with aim of carrying out simultaneous optimization, that is, obtain optimal location in building and optimal mechanical parameters (friction forces) of a maximum number of friction dampers, optimization technique has been improved through linking computational routine based on Finite Differences Method developed in MATLAB by the authors with Firefly Algorithm. Two objective functions of simultaneous optimization of friction dampers are proposed in this work: (i) maximum displacement at the top of a structure and (ii) maximum interstorey drift. Furthermore, complexity of optimization problem was a criterion to choose metaheuristic techniques, for example, Firefly Algorithm (FA).

Calculating objective functions for each arrangement of friction dampers requires a dynamic analysis of structure during earthquake. According to Miguel [22] it is possible to solve motion equation (see (1)) using Finite Difference Method. Thus, authors developed a computational routine based on Central Finite Difference Method.

$$
M \overrightarrow{\ddot{\mathbf{x}}}(t)+C \overrightarrow{\dot{\mathbf{x}}}(t)+K \overrightarrow{\mathbf{x}}(t)+\vec{F}_{f n}=-M B \overrightarrow{\mathbf{x}}_{\mathbf{g}}(t)
$$

Equation (1) represents dynamic behavior of a multidegree of freedom (MDOF) system with friction dampers and subjected to external force, where $M$ and $K$ are $n \times n$ size structural mass and stiffness matrices, respectively, and $n$ is number of degrees of freedom. Damping matrix $C$ is proportional to $M$ and $K$ matrices, as $C=a M+b K$. The $n$ dimensional vector $\overrightarrow{\mathbf{x}}(t)$ represents the relative displacement with respect to base and differentiation with respect to time is represented with a dot over displacement vector symbol. Coulomb friction force is represented by $n$-dimensional vector $\vec{F}_{f n}$. B is a $n \times w$ matrix that contains cosine directors of angles formed between base motion and direction of displacement considered degree of freedom (DOF). $w$ is number of directions of ground motion and $\overrightarrow{\mathbf{x}}_{\mathbf{g}}(t)$ is $w$ dimensional ground acceleration vector of seismic excitation. Coulomb friction force is represented by (2) where $\mu$ is the friction coefficient (assumed as constant), $N$ is normal force vector, $\operatorname{sgn}()$ is sign function, and $v(t)$ is relative velocity vector between ends of damper.

$$
F_{f n}=\mu N \operatorname{sgn}(v(t))
$$

It is important to highlight that magnitude of friction force is constant but its direction is always opposite to sliding velocity. The changes in direction of velocity cause discontinuities in friction force, leading to difficulties in evaluating response of a system with friction dampers. For this reason, continuous function $f_{2}\left(\alpha_{2} v\right)=\tanh \left(\alpha_{2} v\right)$ with $\alpha_{2}=1 \times 10^{50}$ was implemented, which was proposed by Mostaghel and Davis [23] and represents discontinuity of Coulomb friction force, where $\alpha_{2}$ is parameter that controls level of accuracy of function representing friction force. The continuous function $f_{2}$ was already used in previous studies, for example, [1419, 22].

The friction damper is a device highlighted among passive dampers because of low maintenance cost and high performance to dissipate seismic energy. Behind its performance lies solid friction mechanism that gives desired energy dissipation to control structural response. An example of this sort of device is friction damper (see Figure 1(a)) Model A developed by Miguel [22]. The Model A develops friction force because of two solid bodies sliding in relation to each other. The material used for sliding bodies is brass and control of normal force at contact between two solid bodies is given by two compression springs. If the reader needs more information about Model A, the authors recommend reading Master Dissertation of Miguel [22]. In this work, placement of friction dampers in structure as diagonal bracing bars was considered as shown in Figure 1(b).

The optimization problem consist in an objective function to be minimized, a search space defined over a set of discrete design variable, and continuous design variables. Appropriate locations for a limited number of friction dampers in a civil structure can be represented by discrete variables and appropriate mechanical parameters for each optimal located damper are best represented by continuous variable. Optimization problem constraints are allowed limits for friction forces (lower bound $\leq \vec{F}_{f n} \leq$ upper bound), 


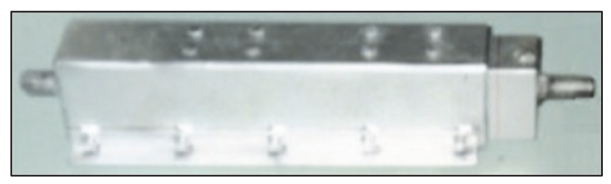

(a)

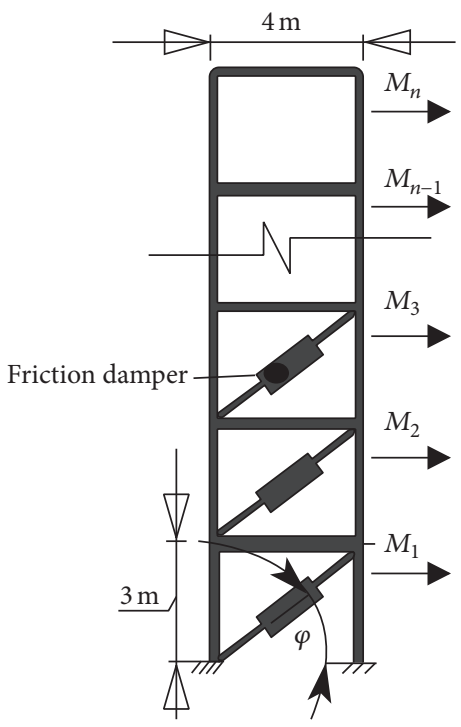

(b)

FIgURE 1: (a) Friction damper Model A; (b) n-storey structure with friction dampers.

TABLE 1: Objective functions.

\begin{tabular}{lcc}
\hline Find & $\overrightarrow{\mathbf{y}}$ \\
\hline Minimize & $\mathbf{J}_{\mathbf{1}}(\overrightarrow{\mathbf{y}})=D_{\max }(\overrightarrow{\mathbf{y}})$ & $\mathbf{J}_{\mathbf{2}}(\overrightarrow{\mathbf{y}})=d_{\max }(\overrightarrow{\mathbf{y}})$ \\
\hline Subjected to & $F_{f n}^{\min } \leq F_{f n}^{j} \leq F_{f n}^{\max }$, & $j=1, \ldots, n_{d}$ \\
& $n_{p}$ (number of available positions) \\
& $n_{d}$ (maximum number of dampers) \\
\hline
\end{tabular}

number of available positions $\left(n_{p}\right)$ in structure for installation of a maximum number of friction dampers $\left(n_{d}\right)$. As was mentioned above, positions for each passive device in structure are best represented as discrete design variable. Thus, $\vec{P}$ is $n_{p}$-dimensional vector of damper positions containing 0 and 1 ; that is, 1 indicates that there is a damper in that position. Thus, maximum number of ones in $\vec{P}$ is $n_{d}$. On the other hand, friction forces $\vec{F}_{f n}$ of each friction damper are better represented as continuous design variables. With aim of presenting a correct notation, design variables are grouped into design vector $\overrightarrow{\mathbf{y}}=\left[\begin{array}{ll}\vec{P} & \vec{F}_{f n}\end{array}\right]$. Two optimization problems can be posed as shown in Table 1, where first objective function $\mathbf{J}_{\mathbf{1}}(\overrightarrow{\mathbf{y}})$ is minimize maximum displacement at top of structure $D_{\max }(\overrightarrow{\mathbf{y}})$ and second objective function $\mathbf{J}_{2}(\overrightarrow{\mathbf{y}})$ is minimize maximum interstorey drift in structure $d_{\max }(\vec{y})$ with same constraints mentioned above for two objective functions.

\section{Firefly Algorithm}

This metaheuristic optimization methodology was developed by Yang [24] based on characteristic bioluminescence of fireflies, that is, coleopteran insects notorious for their light emissions. In later years, several researches have been focused on solving structural optimization and damper optimization problems implementing Firefly Algorithm, as is presented in some works in literature, for example, [20, 25-36].

The Firefly Algorithm will evaluate objective function after solving motion equation for each optimal arrangement of friction dampers through computational routine based on Central Finite Difference Method developed by the authors. For each iteration a number $p$ of objective functions are evaluated where fireflies' population is $p$; in other words each firefly will evaluate one objective function. For purposes of guaranteeing optimal response and preventing Firefly Algorithm from converging to local optimum, fireflies' population was set to fifty fireflies and iterations to one thousand. Two stopping criteria were taken into account; first one is maximum number of iterations $\left(t_{\max }\right.$ ) (also called generation number) set to one thousand; second one is a consecutive number of iterations $\left(t_{k}\right)$ without change in incumbent (best objective function $\mathbf{J}\left(\mathbf{y}_{i}\right)$ associated with best firefly in current iteration) settled to one hundred iterations. Thus, Firefly Algorithm may be stopped by either of two stop criteria. It is worth highlighting that stop criteria developed reduces computational time, in best case, up to a third of the time spent by stop criteria of number of iterations. In order to summarize information presented before, a flowchart of Firefly Algorithm is presented in Figure 2. Besides, if the reader requires more information about Firefly Algorithm, the authors recommend the book Yang [24], which provides several details about optimization methodology and computational code of Firefly Algorithm.

\section{Numerical Simulations and Illustrative Examples}

In this section, with the aim of illustrating methodology presented above and demonstrating capacity to optimize 


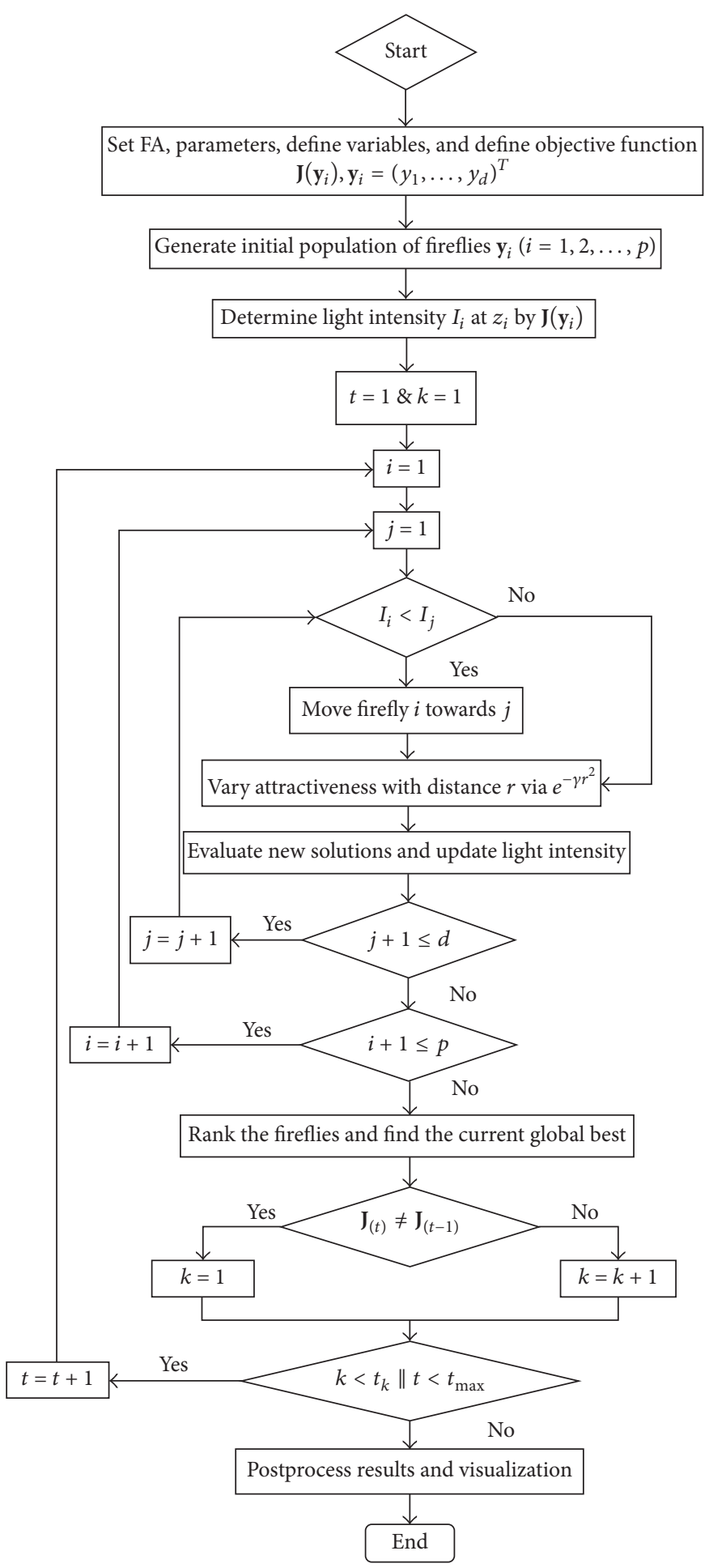

FIGURE 2: Flowchart of the Firefly Algorithm.

dynamic response of a structure under earthquake excitation, two kinds of structures are implemented: a 2D steel building adapted from Miguel et al. [37] and a 3D concrete building located in Cúcuta, Colombia.
As explained above, two objective functions are used to illustrate performance of proposed methodology for optimum design of friction dampers. The two objective functions involve computing of vector $\vec{x}(t)$ through solving 


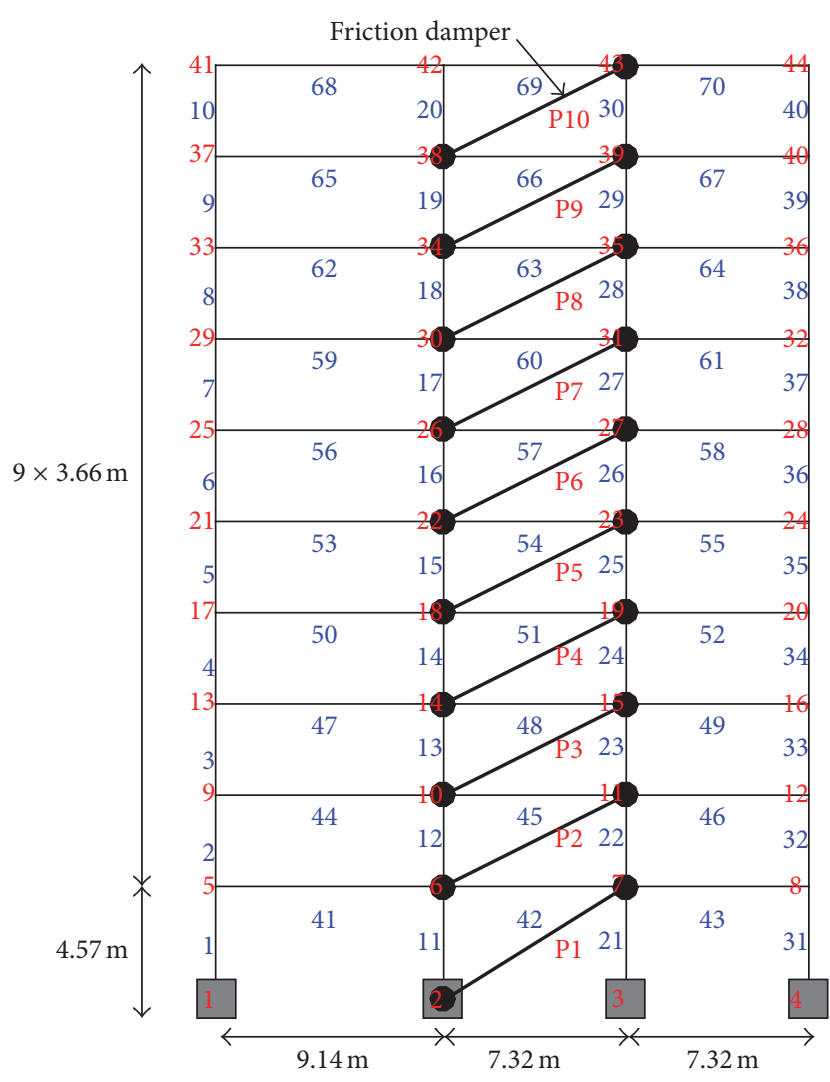

FIGURE 3: Ten-storey steel building.

(1) using finite difference explicit method as was mentioned previously.

4.1. Ten-Storey Steel Building. The first structure analyzed is a steel, three-bay, 10-storey building, $37.51 \mathrm{~m}$ high and $23.78 \mathrm{~m}$ wide, shown in Figure 3, in which it is also shown diagonal disposition of friction dampers. The structure is modeled as a FE 2D frame structure consisting of 70 elements and 44 nodes, that is, 132 degrees of freedom. The finite element is a $2 \mathrm{D}$ beam element with three degrees of freedom per node. The mass and stiffness matrices of element are present below in (3) and (4), respectively.

$$
\begin{aligned}
& m_{e} \\
& =\left[\begin{array}{cccccc}
\frac{\rho A l}{3} & 0 & 0 & \frac{\rho A l}{6} & 0 & 0 \\
0 & \frac{13 \rho A l}{35} & \frac{11 \rho A l^{2}}{210} & 0 & \frac{9 \rho A l}{70} & -\frac{13 \rho A l^{2}}{420} \\
0 & \frac{11 \rho A l^{2}}{210} & \frac{\rho A l^{3}}{105} & 0 & \frac{13 \rho A l^{2}}{420} & -\frac{\rho A l^{3}}{140} \\
\frac{\rho A l}{6} & 0 & 0 & \frac{\rho A l}{3} & 0 & 0 \\
0 & \frac{9 \rho A l}{70} & \frac{13 \rho A l^{2}}{420} & 0 & \frac{13 \rho A l}{35} & -\frac{11 \rho A l^{2}}{210} \\
0 & -\frac{13 \rho A l^{2}}{420} & -\frac{\rho A l^{3}}{140} & 0 & -\frac{11 \rho A l^{2}}{210} & \frac{\rho A l^{3}}{105}
\end{array}\right]
\end{aligned}
$$

$$
k_{e}=\left[\begin{array}{cccccc}
\frac{E A}{l} & 0 & 0 & -\frac{E A}{l} & 0 & 0 \\
0 & \frac{12 I_{z z} E}{l^{3}} & \frac{6 I_{z z} E}{l^{2}} & 0 & \frac{12 I_{z z} E}{l^{3}} & \frac{6 I_{z z} E}{l^{2}} \\
0 & \frac{6 I_{z z} E}{l^{2}} & \frac{4 I_{z z} E}{l} & 0 & -\frac{6 I_{z z} E}{l^{2}} & \frac{2 I_{z z} E}{l} \\
-\frac{E A}{l} & 0 & 0 & \frac{E A}{l} & 0 & 0 \\
0 & \frac{12 I_{z z} E}{l^{3}} & -\frac{6 I_{z z} E}{l^{2}} & 0 & \frac{12 I_{z z} E}{l^{3}} & -\frac{6 I_{z z} E}{l^{2}} \\
0 & \frac{6 I_{z z} E}{l^{2}} & \frac{2 I_{z z} E}{l} & 0 & -\frac{6 I_{z z} E}{l^{2}} & \frac{4 I_{z z} E}{l}
\end{array}\right]
$$

in which $\rho$ is specific mass, $A$ is cross-sectional area, $l$ is element length, $E$ is Young's modulus, and $I_{z z}$ is moment of inertia. Geometrical properties of members of structure are presented in Table 2.

As well-known Finite Difference Method employed in this work is a conditionally stable method, it requires using a time integration step $\Delta t$ less than a critical time step $\Delta t_{\mathrm{cr}}$. Thus, critical time step is calculated using (5) as suggested by Rao and Yap [38].

$$
\Delta t \leq \Delta t_{\mathrm{cr}}=\frac{2}{\omega_{n n}}
$$

in which $\omega_{n n}$ is largest natural frequency of structure. Thus, for this case, time step $\Delta t$ equal to $3 E-4 \mathrm{~s}$ is used to solve motion equation (see (1)). It is noteworthy that, in a steel structure, damping ratio $(\zeta)$ considered for first and second vibration modes is $0.7 \%$ of critical damping ( $a=$ 0.1493 and $b=2.6523 \times 10^{-4}$ ). The first six natural frequencies of structure are 2.3609, 6.0399, 9.9620, 14.5769, 20.1192, and $26.1602 \mathrm{~Hz}$. As may be seen in Figure 3, there are ten predefined possible positions $\left(n_{p}=10\right)$ for friction dampers $\left(P_{1}, P_{2}, P_{3}, \ldots, P_{10}\right)$. The dampers are assumed to be installed between neighboring stories by braces. The ten-storey building is subjected to generated Kanai-Tajimi excitation for three kinds of soils. In the next section method to simulate seismic loads is presented.

4.1.1. Simulation Seismic Loading. As was mentioned above, part of motion equation is seismic acceleration $\ddot{x}_{g}$. As a dynamic load a one-dimensional artificial earthquake was implemented where acceleration is zero-mean normal random processes simulated by superposition of harmonic waves, as shown by Shinozuka and Jan [39]. The Spectral Representation Method is best represented by

$$
\vec{x}_{g}(t)=\sum_{j=1}^{N} \sqrt{2 S_{\omega}\left(f_{j}\right) \Delta f_{j}} \cos \left(2 \pi f_{j} t+\phi_{j}\right) \text {. }
$$

In this method, frequency band of interest must be divided into $N$ intervals, such that $\Delta f_{j}=f_{j+1}+f_{j}$ and $\phi_{j}$ is phase angle, which is a random variable with a uniform probability distribution function between 0 and $2 \pi$. On the other hand, power spectral density function $S_{\omega}$ (see (7) and Figure 4) used 
TABLE 2: Geometrical properties of the 10-storey building.

\begin{tabular}{lccc}
\hline Member number & W shape & Area $\left[\mathrm{m}^{2}\right]$ & Inertia moment $\left[\mathrm{m}^{4}\right]$ \\
\hline 1,2 & W $360 \times 216$ & $2.76 E-2$ & $7.12 E-4$ \\
$3,4,17,18,27,28,33,34$ & W $360 \times 162$ & $2.06 E-2$ & $5.16 E-4$ \\
5,6 & W $360 \times 122$ & $1.55 E-2$ & $3.65 E-4$ \\
$7,8,37,38$ & W $360 \times 91$ & $1.16 E-2$ & $2.67 E-4$ \\
$9,10,39,40$ & W $360 \times 64$ & $8.14 E-2$ & $1.78 E-4$ \\
11,12 & W $360 \times 314$ & $3.99 E-2$ & $1.10 E-4$ \\
13,14 & W $360 \times 262$ & $3.35 E-2$ & $8.94 E-4$ \\
$15,16,31,32$ & W $360 \times 196$ & $2.50 E-2$ & $6.36 E-4$ \\
$19,20,29,30$ & W $360 \times 101$ & $1.29 E-2$ & $3.01 E-4$ \\
21,22 & W $360 \times 287$ & $3.66 E-2$ & $9.97 E-4$ \\
23,24 & W $360 \times 237$ & $3.01 E-2$ & $7.88 E-4$ \\
25,26 & W $360 \times 179$ & $2.28 E-2$ & $5.75 E-4$ \\
35,36 & W $360 \times 110$ & $1.40 E-2$ & $3.31 E-4$ \\
$41,42,43$ & W $610 \times 113$ & $1.45 E-2$ & $8.75 E-4$ \\
$44,45,46$ & W $610 \times 101$ & $1.30 E-2$ & $7.64 E-4$ \\
$47,48,49$ & W $610 \times 92$ & $1.18 E-2$ & $6.51 E-4$ \\
$50,51,52,53,54,55$ & W $530 \times 85$ & $1.08 E-2$ & $4.85 E-4$ \\
$56,57,58,59,60,61$ & W $530 \times 74$ & $9.53 E-3$ & $4.11 E-4$ \\
$62,63,64,65$ & W $530 \times 66$ & $8.38 E-3$ & $3.51 E-4$ \\
$66,67,68$ & W $460 \times 52$ & $6.63 E-3$ & $2.12 E-4$ \\
69,70 & W $360 \times 39$ & $4.98 E-3$ & $1.02 E-4$ \\
\hline
\end{tabular}

TABLE 3: Soil and earthquakes parameters.

\begin{tabular}{lccc}
\hline Soil type & $\omega_{g}(\mathrm{rad} / \mathrm{s})$ & $\zeta_{g}$ & Earthquake duration $(\mathrm{s})$ \\
\hline Rock & $8 \pi$ & 0.6 & 15 \\
Stiff soil & $5 \pi$ & 0.6 & 20 \\
Soft soil & $2.4 \pi$ & 0.85 & 25 \\
\hline
\end{tabular}

in this paper is proposed by Kanai [40] and Tajimi [41] known as Kanai-Tajimi filter technique

$$
\begin{aligned}
S_{g}(\omega) & =S_{0}\left[\frac{1+4 \zeta_{g}^{2}\left(\omega^{2} / \omega_{g}^{2}\right)}{\left[1-\omega^{2} / \omega_{g}^{2}\right]^{2}+4 \zeta_{g}^{2}\left(\omega^{2} / \omega_{g}^{2}\right)}\right] \\
S_{0} & =\frac{A_{P}^{2}}{P_{g}^{2}\left[\pi \omega_{g}\left(1 / 2 \zeta_{g}+2 \zeta_{g}\right)\right]}
\end{aligned}
$$

in which $S_{g}(\omega)$ is earthquake power spectrum, $S_{0}$ is intensity of spectrum, $\omega_{g}$ is dominant ground frequency, and $\zeta_{g}$ is critical damping parameter. The parameter $S_{0}$ is related to peak ground acceleration (PGA), where $A_{P}$ is the PGA value assumed as $35 \%$ of gravity and $P_{g}$ is peak factor taken as 3 . Three values of $\omega_{g}$ and $\zeta_{g}$ are presented by Seya et al. [42] as representative values of three kinds of soil: soft soil, stiff soil, and rock. The parameters of Kanai-Tajimi power spectra for three soil conditions and total duration of earthquake acceleration are listed in Table 3.

The Kanai-Tajimi power spectrum for each soil scenario and PGA of $0.35 \mathrm{~g}$ are shown in Figure 4(a). Given three different power spectra, earthquake time histories can be developed by using superposition of harmonic waves method as was mentioned above and three accelerograms for each soil scenario are also shown in Figures 4(b), 4(c), and 4(d).

4.1.2. Optimization Results of the Ten-Storey Building. In order to illustrate the methodology, the ten-storey building is studied taking into account the three kinds of soils presented above. The constraints for three optimization problems are the same. Thus, the number of predefine positions $n_{p}$ is equal to ten and maximum number of dampers $n_{d}$ to be installed in structure is equal to three. The allowable limit for friction forces for each device is $\left(64.489 \mathrm{kN} \leq \vec{F}_{f n} \leq 78.819 \mathrm{kN}\right)$. The population size and number of generations of Firefly Algorithm are 50 and 1000 , respectively. It is important to highlight that the sum of friction forces of optimal devices does not exceed $50 \%$ of weight of structure, which is equal to $214.96 \mathrm{kN}$.

For rock soil, positions of friction dampers do not change and friction forces are similar in two independent runs for each objective functions. This is an advantage for design engineers for design of friction dampers, because there are two possible designs and both of them achieve a significant reduction in the structural response. Table 4 shows a comparison of two independent runs for each objective function. It is worthy to highlight achieved reduction of $66 \%$ for each one, preventing damage or collapse of structure.

Figures 5(a) and 5(c) illustrate a considerable reduction on structural response in terms of displacement at Node 44 and interstorey drift between fourth and fifth storey 


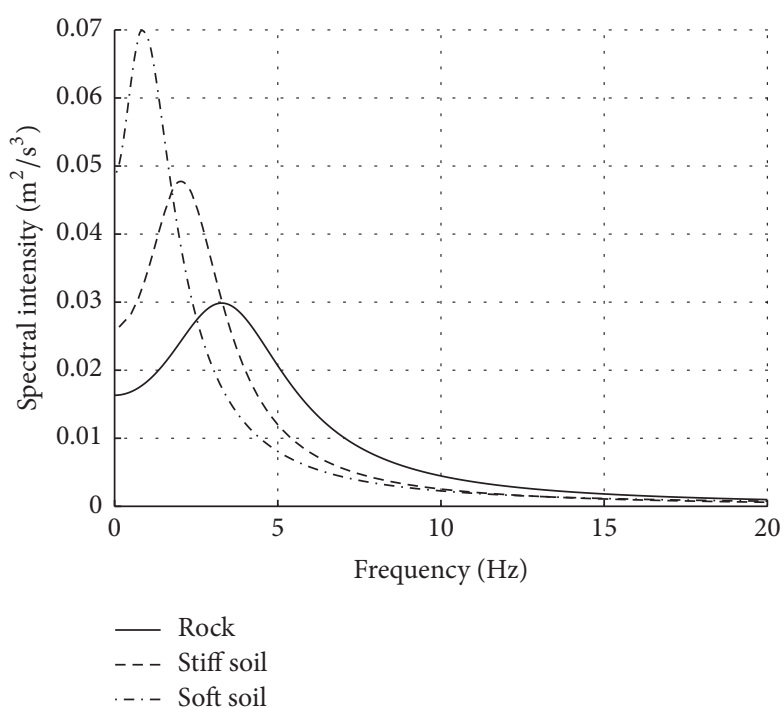

(a)

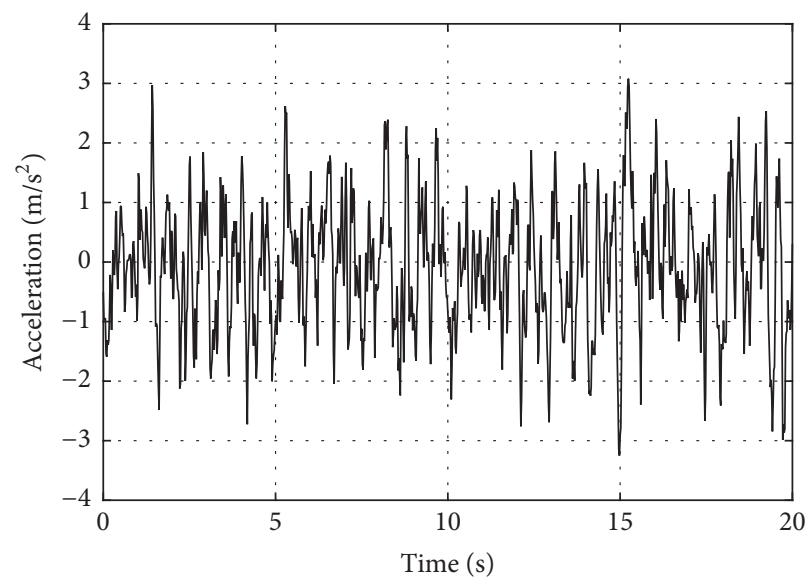

(c)

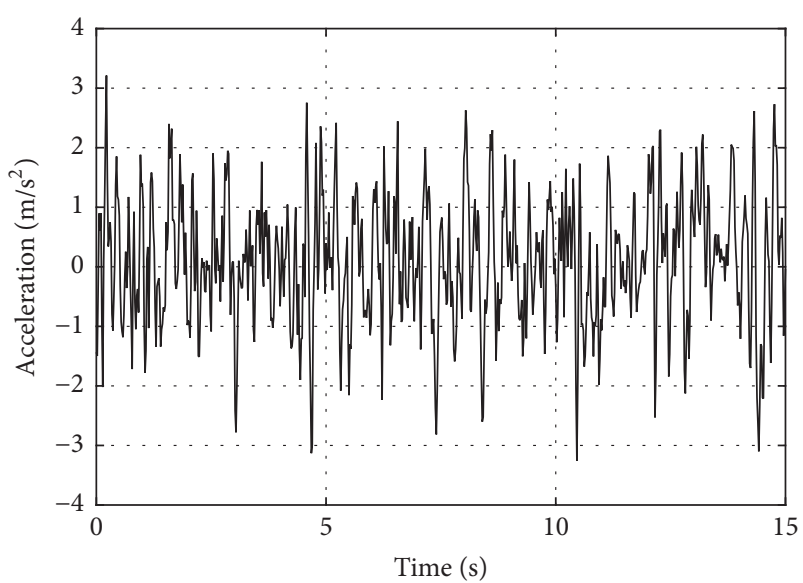

(b)

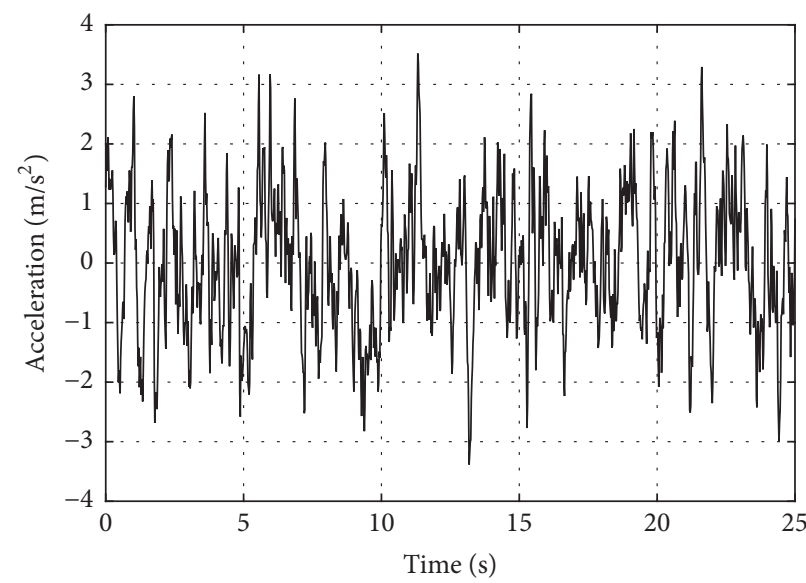

(d)

FIGURE 4: (a) Kanai-Tajimi power spectra corresponding to three soil scenarios. (b) Rock soil accelerogram. (c) Stiff soil accelerogram. (d) Soft soil accelerogram.

TABLE 4: Optimal force and placement of friction dampers for rock soil.

\begin{tabular}{|c|c|c|c|c|}
\hline Run & Optimal position $\vec{P}$ & Optimal friction forces $\vec{F}_{f n}[\mathrm{kN}]$ & Maximum displacement at Node $44[\mathrm{~m}]$ & Reduction (\%) \\
\hline - & Without dampers & Uncontrolled structure & 0.0726 & - \\
\hline 1 & [1010100000] & {$[76.808 ; 68.273 ; 65.325]$} & 0.0243 & 66.5 \\
\hline 2 & [1010100000] & {$[77.104 ; 64.833 ; 71.152]$} & 0.0243 & 66.5 \\
\hline Run & Optimal Position $\vec{P}$ & Optimal friction forces $\vec{F}_{f n}[\mathrm{kN}]$ & Maximum interstorey drift $d_{\max }[\mathrm{m}]$ & Reduction (\%) \\
\hline- & Without dampers & Uncontrolled structure & 0.0098 & - \\
\hline 1 & [1010100000] & {$[70.958 ; 70.384 ; 67.919]$} & 0.0033 & 66.32 \\
\hline 2 & [1010100000] & [73.548; 71.912; 69.522] & 0.0033 & 66.32 \\
\hline
\end{tabular}

after installation of optimized friction damper on optimal locations. Figures 5(b) and 5(d) illustrate maximum displacement per storey and the maximum interstorey drift per storey, respectively, thus allowing having an idea of structure's behavior before and after installation of optimized friction dampers and thus showing the efficiency of said devices.
With the aim of demonstrating effectiveness of friction damper optimization method in another way, optimal solution presented in Table 4 is compared with two alternative methods for damper's location. The first alternative method is locating three optimized friction dampers, in a different position from optimized one. The second one is installing a 


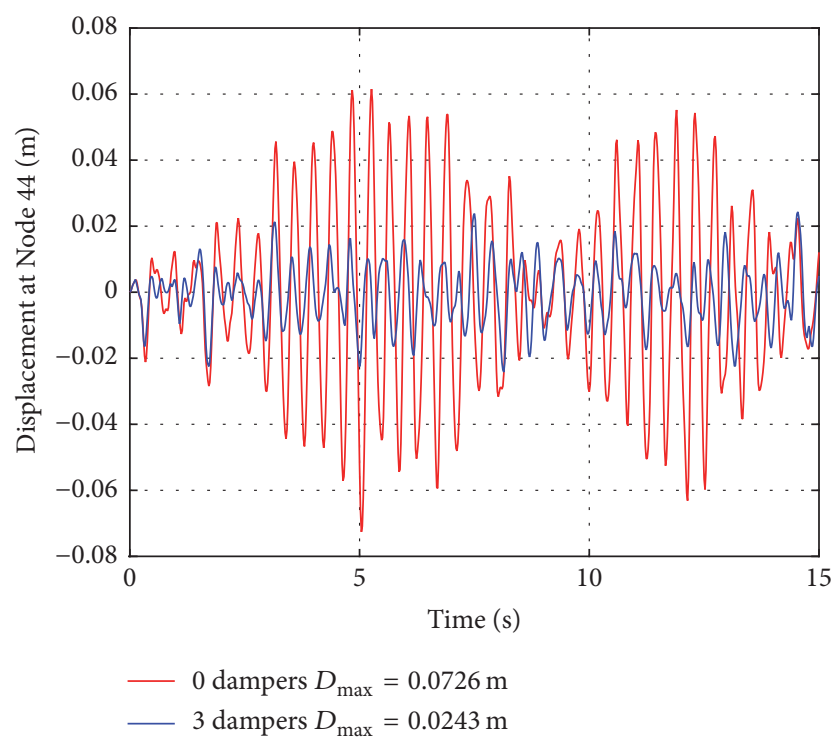

(a)

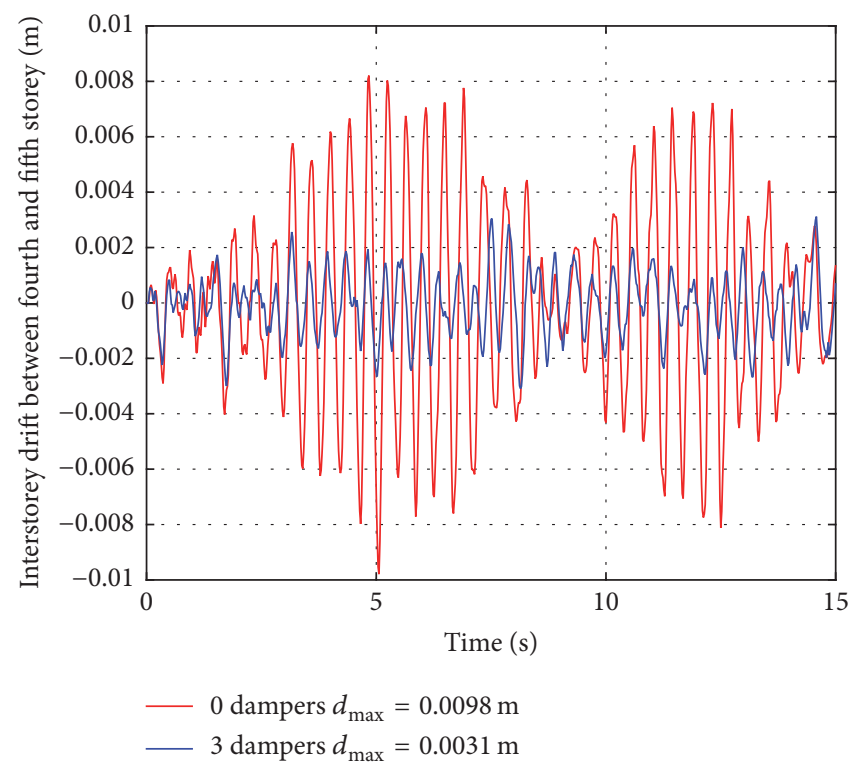

(c)

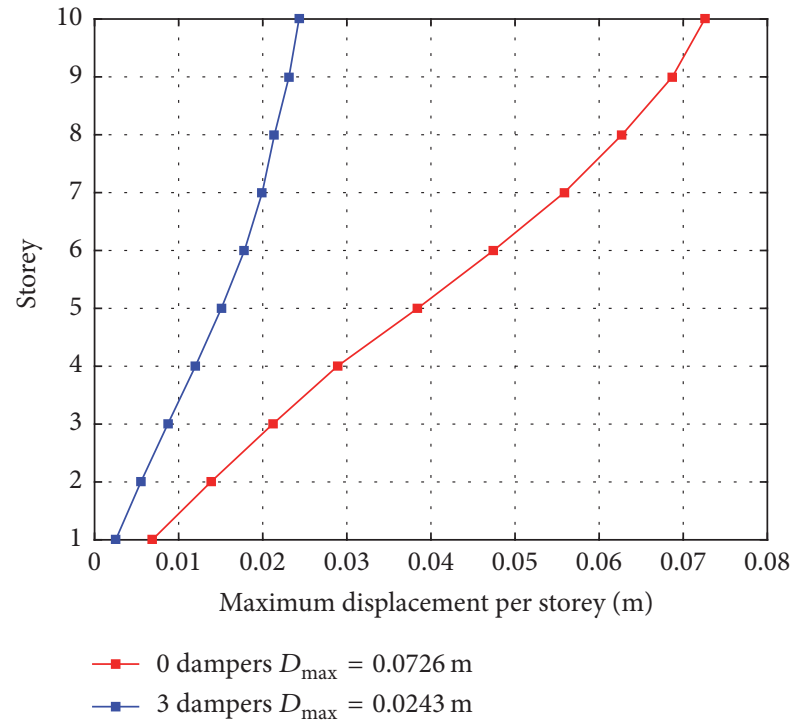

(b)

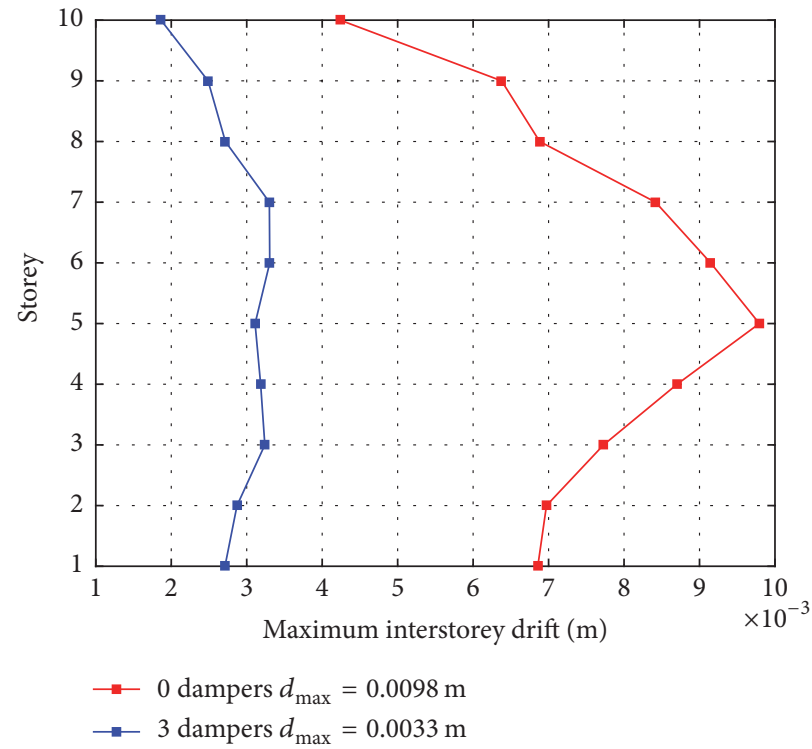

(d)

FIGURE 5: Structural response for rock soil scenario without control (red curve) and with three optimal friction dampers (blue curve). (a) Displacement at Node 44. (b) Envelope diagrams of maximum displacement per storey. (c) Interstorey drift between fourth and fifth storey. (d) Envelope diagrams of maximum interstorey drift.

friction damper on each storey (one damper on each predefine possible positions $\left(n_{p}=10\right)$; see Figure 3 ) with equal friction forces whose sum is equivalent to $50 \%$ of structure's weight. Table 5 shows these comparisons, demonstrating optimization's results presenting a better performance.

In the case of stiff soil, there are no changes in positions of friction dampers for two independent runs for each objective functions, giving two possible designs for design engineers for carrying out design of friction dampers. Both of two possible designs achieve a significant reduction in the structural response. Table 6 shows a comparison of two independent runs for each objective function. As may be seen, reduction achieves $66 \%$ for maximum displacement at Node 44 and $68 \%$ for maximum interstorey drift. Thus, passive control through friction dampers preventing structural integrity is compromised in a seismic event.

The reduction on structural response in terms of displacement at Node 44 and interstorey drift between fourth and fifth storey after installation of optimized friction damper on optimal positions on structure can be seen in Figures 6(a) and 6(c), respectively. On the other hand, Figures 6(b) and $6(\mathrm{~d})$ illustrate maximum displacement per storey and maximum interstorey drift per storey, respectively, for a structure located on a stiff soil. As in previous case, optimal 
TABLE 5: Comparison between optimal solution and two alternative methods for rock soil.

\begin{tabular}{lccc}
\hline Method & Position $\vec{P}$ & Friction forces $\vec{F}_{f n}[\mathrm{kN}]$ & Maximum displacement at Node $44[\mathrm{~m}]$ \\
\hline Three optimized dampers & {$[1010100000]$} & {$[76.808 ; 68.273 ; 65.325]$} & 0.0243 \\
Alternative 1 & {$[0001001001]$} & {$[76.808 ; 68.273 ; 65.325]$} & 0.0381 \\
Alternative 2 & {$[1111111111]$} & 21.496 for each damper & 0.0393 \\
\hline Method & Position $\vec{P}$ & Friction forces $\vec{F}_{f n}[\mathrm{kN}]$ & Maximum interestorey drift $d_{\text {max }}[\mathrm{m}]$ \\
\hline Three optimized dampers & {$[1010100000]$} & {$[70.958 ; 70.384 ; 67.919]$} & 0.0033 \\
Alternative 1 & {$[0001001001]$} & {$[70.958 ; 70.384 ; 67.919]$} & 0.0054 \\
Alternative 2 & {$[1111111111]$} & 21.496 for each damper & 0.0050 \\
\hline
\end{tabular}

TABLE 6: Optimal force and placement of friction dampers for stiff soil.

\begin{tabular}{lcccc}
\hline Run & Optimal position $\vec{P}$ & Optimal friction forces $\vec{F}_{f n}[\mathrm{kN}]$ & Maximum displacement at Node $44[\mathrm{~m}]$ & Reduction $(\%)$ \\
\hline- & Without dampers & Uncontrolled structure & 0.1311 & 0.0447 \\
1 & {$[0011100000]$} & {$[77.619 ; 77.606 ; 70.321]$} & 0.0446 & 65.90 \\
2 & {$[0011100000]$} & {$[77.167 ; 71.597 ; 76.854]$} & 65.98 \\
\hline Run & Optimal position $\vec{P}$ & Optimal friction forces $\vec{F}_{f n}[\mathrm{kN}]$ & Maximum interstorey drift $d_{\text {max }}[\mathrm{m}]$ & Reduction $(\%)$ \\
\hline- & Without dampers & Uncontrolled structure & 0.0176 & - \\
1 & {$[1010100000]$} & {$[78.055 ; 71.420 ; 76.501]$} & 0.0055 & 6.0056 \\
2 & {$[1010100000]$} & {$[74.418 ; 74.794 ; 68.894]$} & 68.18 \\
\hline
\end{tabular}

TABLE 7: Comparison between optimal solution and two alternative methods for stiff soil.

\begin{tabular}{lccc}
\hline Method & Position $\vec{P}$ & Friction forces $\vec{F}_{f n}[\mathrm{kN}]$ & Maximum displacement at Node $44[\mathrm{~m}]$ \\
\hline Three optimized dampers & {$[0011100000]$} & {$[77.619 ; 77.606 ; 70.321]$} & 0.0447 \\
Alternative 1 & {$[0001001001]$} & {$[77.619 ; 77.606 ; 70.321]$} & 0.0697 \\
Alternative 2 & {$[1111111111]$} & 21.496 for each damper & 0.0955 \\
\hline Method & Position $\vec{P}$ & Friction forces $\vec{F}_{f n}[\mathrm{kN}]$ & Maximum interstorey drift $d_{\text {max }}[\mathrm{m}]$ \\
\hline Three optimized dampers & {$[1010100000]$} & {$[78.055 ; 71.420 ; 76.501]$} & 0.0055 \\
Alternative 1 & {$[0001001001]$} & {$[78.055 ; 71.420 ; 76.501]$} & 0.0130 \\
Alternative 2 & {$[1111111111]$} & 21.496 for each damper & 0.0128 \\
\hline
\end{tabular}

TABLE 8: Optimal force and placement of friction dampers for soft soil.

\begin{tabular}{|c|c|c|c|c|}
\hline Run & Optimal position $\vec{P}$ & Optimal friction forces $\vec{F}_{f n}[\mathrm{kN}]$ & Maximum displacement at Node $44[\mathrm{~m}]$ & Reduction (\%) \\
\hline- & Without dampers & Uncontrolled structure & 0.1161 & - \\
\hline 1 & [1010100000] & {$[76.590 ; 70.145 ; 71.534]$} & 0.0292 & 74.84 \\
\hline 2 & [1010100000] & {$[77.051 ; 66.140 ; 74.230]$} & 0.0285 & 75.45 \\
\hline Run & Optimal position $\vec{P}$ & Optimal friction forces $\vec{F}_{f n}[\mathrm{kN}]$ & Maximum interstorey drift $d_{\max }[\mathrm{m}]$ & Reduction (\%) \\
\hline- & Without dampers & Uncontrolled structure & 0.0156 & - \\
\hline 1 & [1010100000] & {$[72.616 ; 68.688 ; 67.258]$} & 0.0037 & 76.28 \\
\hline 2 & [1010100000] & {$[77.218 ; 67.538 ; 70.578]$} & 0.0036 & 76.92 \\
\hline
\end{tabular}

solution presented in Table 6 is compared with two alternative methods for damper's location. The comparisons shown at Table 7 demonstrated that optimal solutions have a better performance than solutions of both alternative methods.

Finally, for soft soil case, there are not changes on positions of friction dampers for two independent runs for each objective functions. The two possible designs presented in Table 8 achieve a significant reduction in the structural response for each objective function. As may be seen, reduction achieves $75 \%$ for maximum displacement at Node 44 and $76 \%$ for maximum interstorey drift. Thus, passive control through friction dampers preventing structural integrity is compromised in a seismic event on soft soil.

The reduction in structural response in terms of displacement at Node 44 and interstorey drift between fourth and fifth storey after installation of optimized friction damper on 


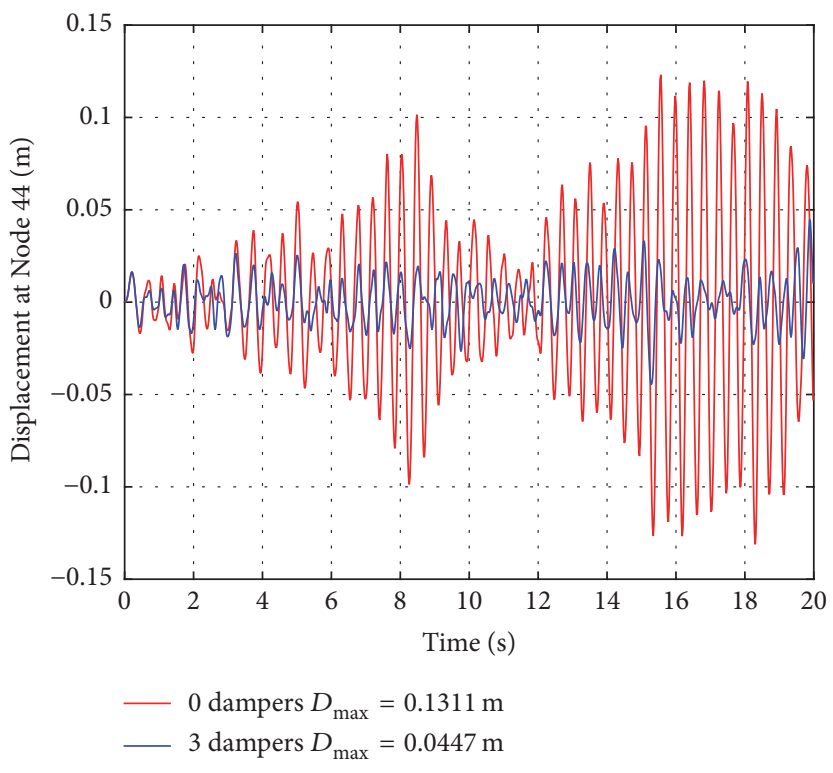

(a)

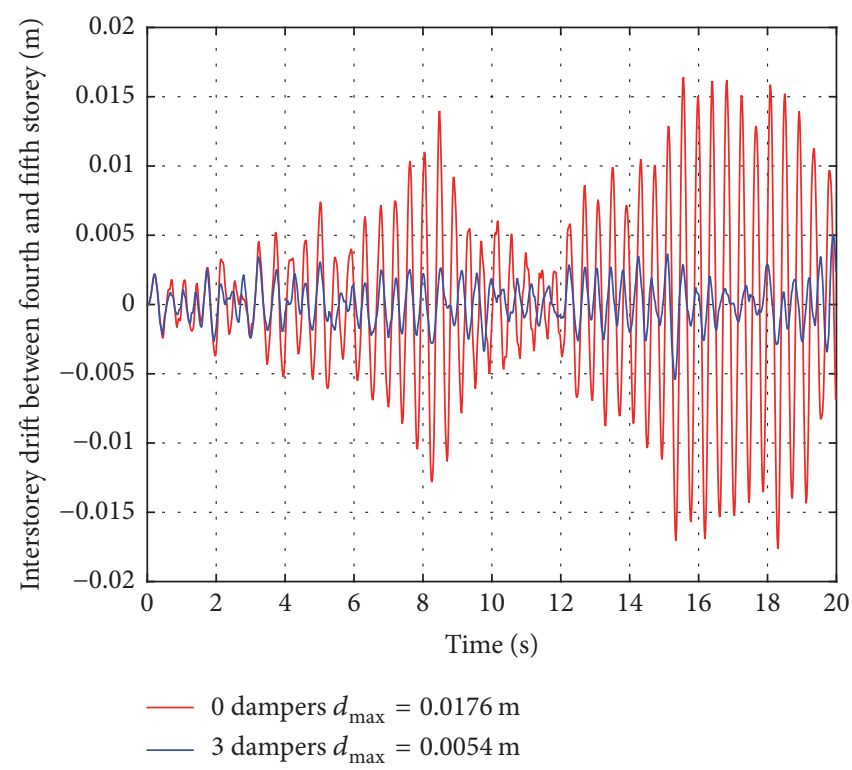

(c)

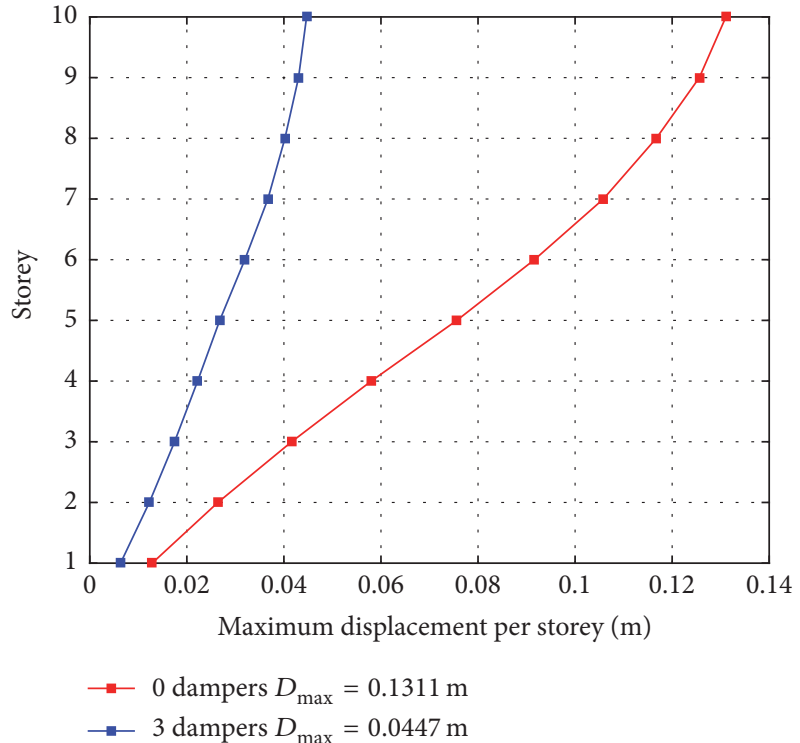

(b)

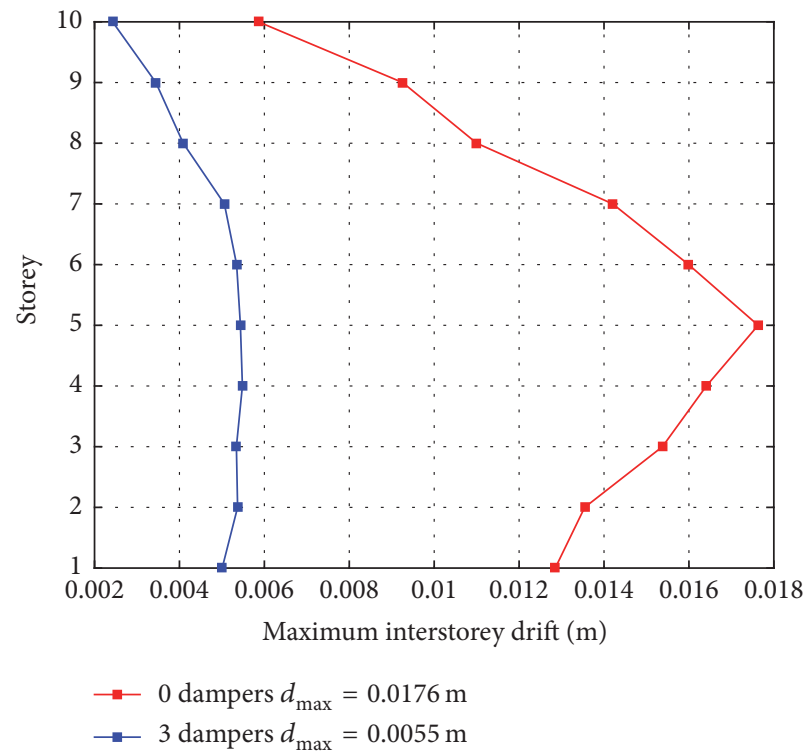

(d)

FIGURE 6: Structural response for stiff soil scenario without control (red curve) and with three optimal friction dampers (blue curve). (a) Displacement at Node 44. (b) Envelope diagrams of maximum displacement per storey. (c) Interstorey drift between fourth and fifth storey. (d) Envelope diagrams of maximum interstorey drift.

optimal positions on structure can be seen in Figures $7(a)$ and 7 (c), respectively. Figures 7(b) and 7(d) illustrate maximum displacement per storey and maximum interstorey drift per storey, respectively, for a structure located on a soft soil.

As in previous cases, optimal solution presented in Table 8 is compared with two alternative methods for damper's location. The comparisons shown at Table 9 demonstrated that optimal solutions have a better performance than solutions of both alternative methods for soft soil scenario.
4.2. Six-Storey Concrete Building. The second structure analyzed is a concrete, three-bay, 6-storey building, $17.1 \mathrm{~m}$ high, $16.55 \mathrm{~m}$ wide, and $7 \mathrm{~m}$ long, shown in Figure 8 , in which diagonal disposition of friction dampers is also shown. The structure is modeled as a FE 3D frame structure consisting of 108 elements and 56 nodes, that is, 336 degrees of freedom. The finite element is a $3 \mathrm{D}$ beam element with six degrees of freedom per node. The mass and stiffness matrices of element are presented below in (8) and (9), respectively. 


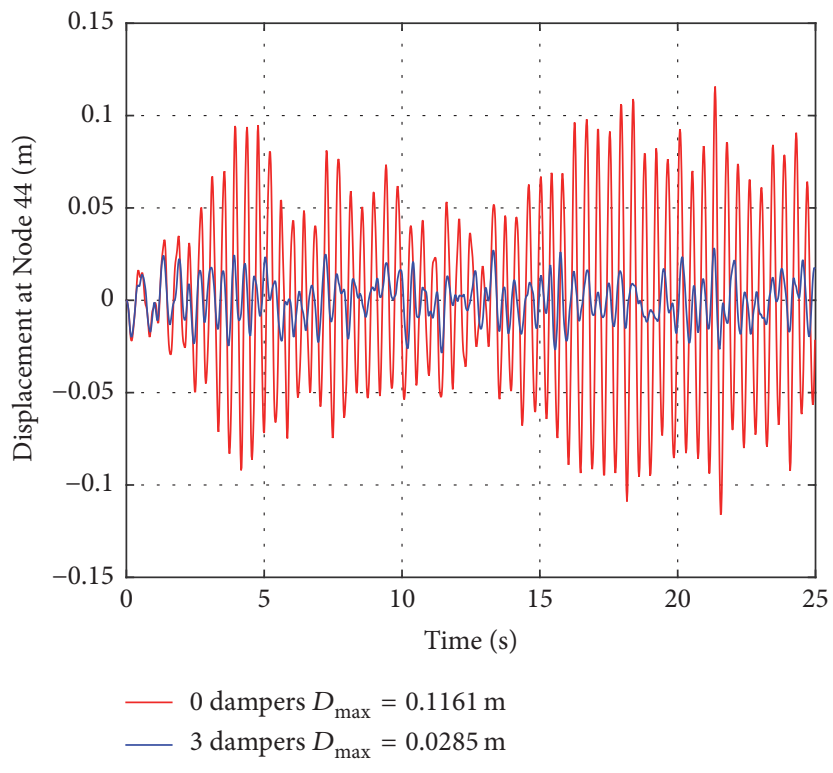

(a)

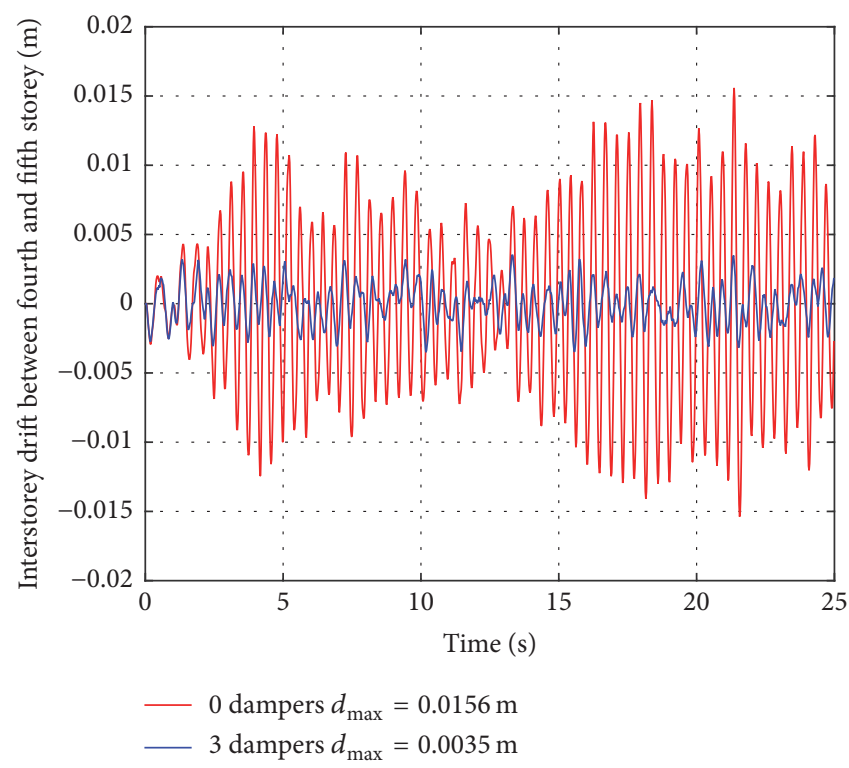

(c)

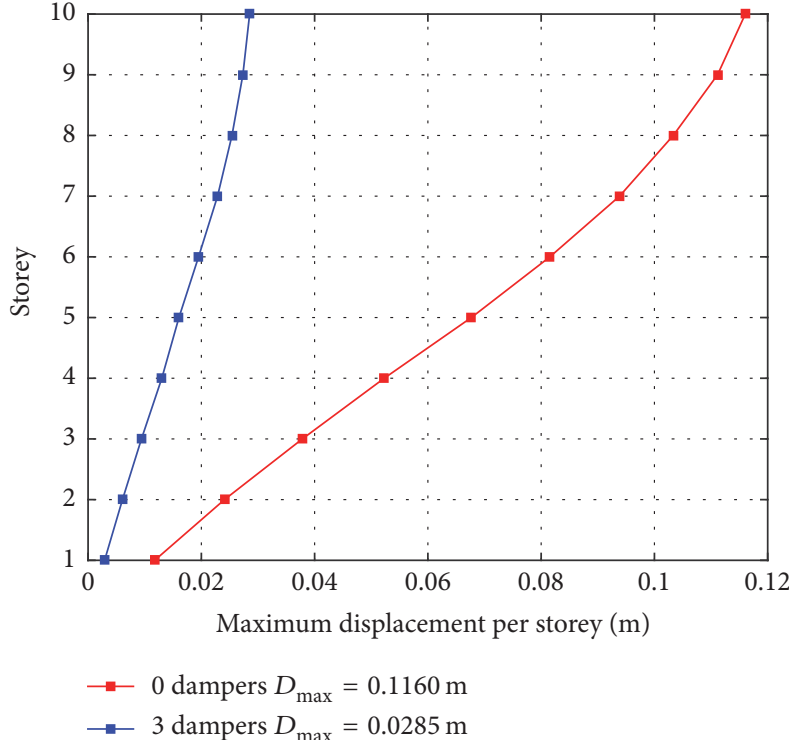

(b)

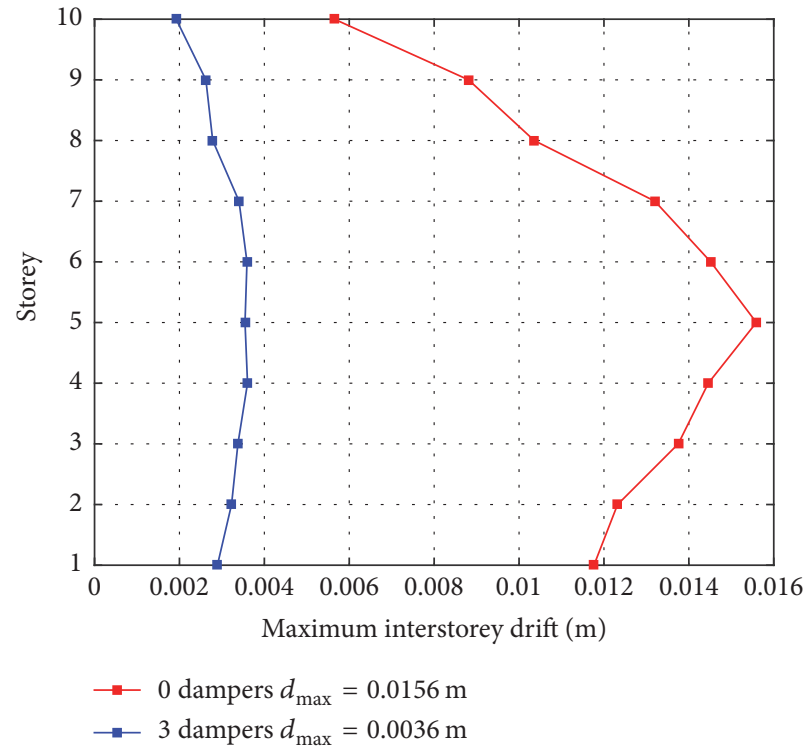

(d)

FIGURE 7: Structural response for soft soil scenario without control (red curve) and with three optimal friction dampers (blue curve). (a) Displacement at Node 44. (b) Envelope diagrams of maximum displacement per storey. (c) Interstorey drift between fourth and fifth storey. (d) Envelope diagrams of maximum interstorey drift.

TABLE 9: Comparison between optimal solution and two alternative methods for soft soil.

\begin{tabular}{lccc}
\hline Method & Position $\vec{P}$ & Friction forces $\vec{F}_{f n}[\mathrm{kN}]$ & Maximum displacement at Node $44[\mathrm{~m}]$ \\
\hline Three optimized dampers & {$[1010100000]$} & {$[76.590 ; 70.145 ; 71.534]$} & 0.0292 \\
Alternative 1 & {$[0001001001]$} & {$[76.590 ; 70.145 ; 71.534]$} & 0.0400 \\
Alternative 2 & {$[1111111111]$} & 21.496 for each damper & 0.0549 \\
\hline Method & Position $\vec{P}$ & Friction forces $\vec{F}_{f n}[\mathrm{kN}]$ & Maximum interstorey drift $d_{\max }[\mathrm{m}]$ \\
\hline Three optimized dampers & {$[1010100000]$} & {$[72.616 ; 68.688 ; 67.258]$} & 0.0037 \\
Alternative 1 & {$[0001001001]$} & {$[72.616 ; 68.688 ; 67.258]$} & 0.0056 \\
Alternative 2 & {$[1111111111]$} & 21.496 for each damper & 0.0076 \\
\hline
\end{tabular}




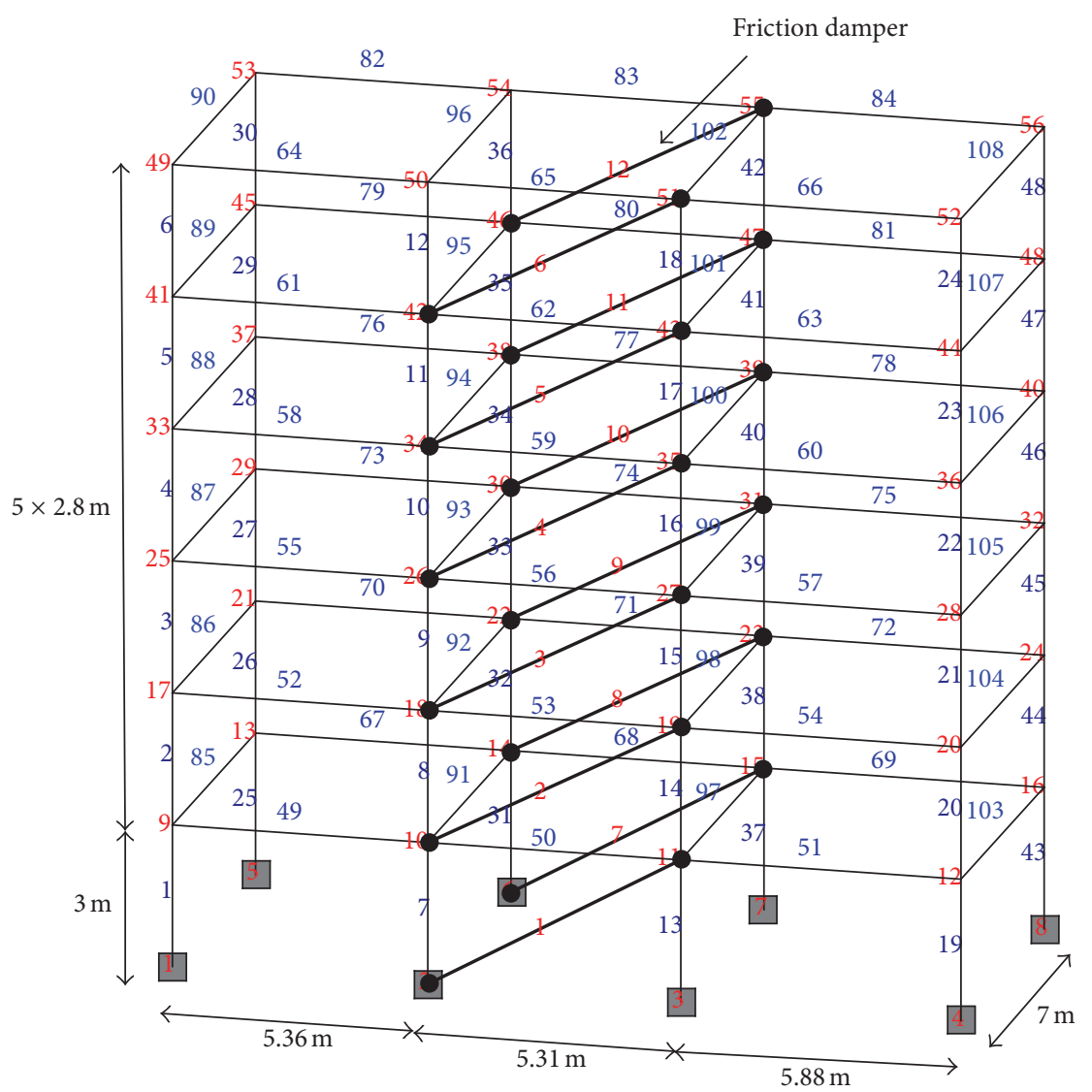

FIGURE 8: Six-storey concrete building.

$$
m_{e}=\frac{\rho A l}{420}\left[\begin{array}{cccccccccccc}
140 & 0 & 0 & 0 & 0 & 0 & 70 & 0 & 0 & 0 & 0 & 0 \\
0 & 156 & 0 & 0 & 0 & 22 l & 0 & 54 & 0 & 0 & 0 & -13 l \\
0 & 0 & 156 & 0 & -22 l & 0 & 0 & 0 & 54 & 0 & 13 l & 0 \\
0 & 0 & 0 & \frac{140 J}{A} & 0 & 0 & 0 & 0 & 0 & \frac{70 J}{A} & 0 & 0 \\
0 & 0 & -22 l & 0 & 4 l^{2} & 0 & 0 & 0 & -13 l & 0 & -3 l^{2} & 0 \\
0 & 22 l & 0 & 0 & 0 & 4 l^{2} & 0 & 13 l & 0 & 0 & 0 & -3 l^{2} \\
70 & 0 & 0 & 0 & 0 & 0 & 140 & 0 & 0 & 0 & 0 & 0 \\
0 & 54 & 0 & 0 & 0 & 13 l & 0 & 156 & 0 & 0 & 0 & -22 l \\
0 & 0 & 54 & 0 & -13 l & 0 & 0 & 0 & 156 & 0 & 22 l & 0 \\
0 & 0 & 0 & \frac{70 J}{A} & 0 & 0 & 0 & 0 & 0 & \frac{140 J}{A} & 0 & 0 \\
0 & 0 & 13 l & 0 & -3 l^{2} & 0 & 0 & 0 & 22 l & 0 & 4 l^{2} & 0 \\
0 & -13 l & 0 & 0 & 0 & -3 l^{2} & 0 & -22 l & 0 & 0 & 0 & 4 l^{2}
\end{array}\right]
$$




$$
k_{e}=\left[\begin{array}{cccccccccccc}
\frac{E A}{l} & 0 & 0 & 0 & 0 & 0 & -\frac{E A}{l} & 0 & 0 & 0 & 0 & 0 \\
0 & \frac{12 E I_{V}}{l^{3}} & 0 & 0 & 0 & \frac{6 E I_{V}}{l^{2}} & 0 & -\frac{12 E I_{V}}{l^{3}} & 0 & 0 & 0 & \frac{6 E I_{V}}{l^{2}} \\
0 & 0 & \frac{12 E I_{H}}{l^{3}} & 0 & -\frac{6 E I_{H}}{l^{2}} & 0 & 0 & 0 & -\frac{12 E I_{H}}{l^{3}} & 0 & -\frac{6 E I_{H}}{l^{2}} & 0 \\
0 & 0 & 0 & \frac{G J}{l} & 0 & 0 & 0 & 0 & 0 & -\frac{G J}{l} & 0 & 0 \\
0 & 0 & -\frac{6 E I_{H}}{l^{2}} & 0 & \frac{4 E I_{H}}{l} & 0 & 0 & 0 & \frac{6 E I_{H}}{l^{2}} & 0 & \frac{2 E I_{H}}{l} & 0 \\
0 & \frac{6 E I_{V}}{l^{2}} & 0 & 0 & 0 & \frac{4 E I_{V}}{l} & 0 & \frac{6 E I_{V}}{l^{2}} & 0 & 0 & 0 & \frac{2 E I_{V}}{l} \\
-\frac{E A}{l} & 0 & 0 & 0 & 0 & 0 & \frac{E A}{l} & 0 & 0 & 0 & 0 & 0 \\
0 & -\frac{12 E I_{V}}{l^{3}} & 0 & 0 & 0 & \frac{6 E I_{V}}{l^{2}} & 0 & \frac{12 E I_{V}}{l^{3}} & 0 & 0 & 0 & -\frac{6 E I_{V}}{l^{2}} \\
0 & 0 & -\frac{12 E I_{H}}{l^{3}} & 0 & \frac{6 E I_{H}}{l^{2}} & 0 & 0 & 0 & \frac{12 E I_{H}}{l^{3}} & 0 & \frac{6 E I_{H}}{l^{2}} & 0 \\
0 & 0 & 0 & -\frac{G J}{l} & 0 & 0 & 0 & 0 & 0 & \frac{G J}{l} & 0 & 0 \\
0 & 0 & -\frac{6 E I_{H}}{l^{2}} & 0 & \frac{2 E I_{H}}{l} & 0 & 0 & 0 & \frac{6 E I_{H}}{l^{2}} & 0 & \frac{4 E I_{H}}{l} & 0 \\
0 & \frac{6 E I_{V}}{l^{2}} & 0 & 0 & 0 & \frac{2 E I_{V}}{l} & 0 & -\frac{6 E I_{V}}{l^{2}} & 0 & 0 & 0 & \frac{4 E I_{V}}{l}
\end{array}\right]
$$

in which $\rho$ is specific mass, $A$ is cross-sectional area, $l$ is element length, $J$ is torsional moment of inertia, $E$ is Young's modulus, $I_{V}$ is moment of inertia about vertical direction, $I_{H}$ is moment of inertia about horizontal direction, and $G$ is shear modulus. The geometrical properties of members of structure are presented in Table 10.

In this second case of study, time step $\Delta t$ was calculated using (5) and is equal to $2 E-4 \mathrm{~s}$. It is known that for concrete structures damping ratio $(\zeta)$ considered for first and second vibration modes is $1 \%$ of critical damping ( $a=0.1192$ and $\left.b=8.3908 \times 10^{-4}\right)$. The first six natural frequencies are 1.8767, $1.9169,2.2497,4.2518,5.1794$, and $5.8208 \mathrm{~Hz}$.

As may be seen in Figure 8, there are twelve predefined possible positions $\left(n_{p}=12\right)$ for friction dampers $P(1,2,3, \ldots, 12)$. The dampers are assumed to be installed between neighboring stories by braces. Since case of study is a 3D concrete building, a real three-component seismic record corresponding to Cordoba earthquake was implemented, which took place in Cordoba city, department of Quindío, Colombia, in January 25 of 1999. Because of this earthquake 1185 people passed away and 8523 people were injured and it caused serious damage in cities of Armenia and Pereira as well as 28 nearby municipalities. The earthquake generated losses of order of 1.591 USD million, corresponding to $1.88 \%$ of the National GDP (Gross Domestic Product) of that year [43].

Thus, in Figure 9 Cordoba seismic record with its three components is illustrated. Besides, if the reader requires three-component seismic record, the authors recommend visiting the website of Colombian geological service.

4.2.1. Optimization Results of the Six-Storey Building. In order to demonstrate friction dampers performance against real earthquakes, such as Cordoba earthquake, which causes a great destruction in many cities in Colombia, and illustrate that the methodology of optimizing friction dampers is reliable and flexible, simultaneous optimization is carried out using three-component Cordoba seismic record. The constraints for two optimization problems are same. Thus, the number of predefined positions $n_{p}$ is equal to twelve and maximum number of dampers $n_{d}$ to be installed in structure is equal to four. On the other hand, allowable limit for friction forces for each device is $\left(249.732 \mathrm{kN} \leq \vec{F}_{f n} \leq\right.$ $305.228 \mathrm{kN}$ ). The population size and number of generations of Firefly Algorithm are 50 and 1000, respectively, and results are presented in Table 11. It is important to highlight that the sum of friction forces of optimal devices does not exceed $70 \%$ of structure's weight which is equal to $158560 \mathrm{kN}$.

The results show that uncontrolled structural response and controlled structural response (structure equipped with friction dampers) vary considerably in this scenario. As could be seen in results presented in Table 11, optimized dampers achieved a reduction of structural response (in terms of displacement at Node 56 and maximum interstorey drift) greater than $80 \%$. As may be seen in Figures 10(a) and 10(c) there is a comparison between structural response in terms of displacement at Node 56 and interstorey drift between first and second storey, respectively, without control and with four optimal dampers in their optimal positions.

Finally, with the aim of demonstrating effectiveness of friction damper optimization method for spatial structures in another way, optimal solution presented in Table 11 is compared with two alternative methods for damper's location. The first alternative method is locating four optimized friction dampers, in a different position from optimized one. The second one is installing a friction damper on each 
TABLE 10: Geometrical properties of the 6-storey building.

\begin{tabular}{|c|c|c|c|}
\hline Member number & Area $\left[\mathrm{m}^{2}\right]$ & Inertia moment $I_{x z}\left[\mathrm{~m}^{4}\right]$ & Inertia moment $I_{z y}\left[\mathrm{~m}^{4}\right]$ \\
\hline 1 to 12 & 0.18 & $54 E-4$ & $13 E-4$ \\
\hline 13 to 36 & 0.15 & $31 E-4$ & $11 E-4$ \\
\hline 37 to 42 & 0.12 & $16 E-4$ & $9 E-4$ \\
\hline 43 to 48 & 0.15 & $31 E-4$ & $11 E-4$ \\
\hline 85 to 96 & 0.12 & $9 E-4$ & $16 E-4$ \\
\hline 97 to 102 & 0.16 & $21 E-4$ & $21 E-4$ \\
\hline 103 to 108 & 0.12 & $9 E-4$ & $16 E-4$ \\
\hline $67,70,73,76,79,82$ & 0.06 & $1 E-4$ & $8 E-4$ \\
\hline 49 to 66 & 0.12 & $9 E-4$ & $16 E-4$ \\
\hline $68,69,71,72,74,75,77,78,80,81,83,84$ & 0.12 & $9 E-4$ & $16 E-4$ \\
\hline
\end{tabular}

TABLE 11: Optimal force and placement of friction dampers.

\begin{tabular}{|c|c|c|c|c|}
\hline Run & Optimal position $\vec{P}$ & Optimal friction forces $\vec{F}_{f n}[\mathrm{kN}]$ & Maximum displacement at Node 56 & Reduction (\%) \\
\hline- & Without dampers & Uncontrolled structure & 0.2606 & - \\
\hline 1 & [010000111000] & {$[302.621 ; 304.719 ; 286.548 ; 302.900]$} & 0.0303 & 88.37 \\
\hline 2 & {$[010000111000]$} & {$[295.467 ; 303.425 ; 299.925 ; 300.450]$} & 0.0302 & 88.39 \\
\hline Run & Optimal position $\vec{P}$ & Optimal friction forces $\vec{F}_{f n}[\mathrm{kN}]$ & Maximum interstorey drift $d_{\max }[\mathrm{m}]$ & Reduction (\%) \\
\hline- & Without dampers & Uncontrolled structure & 0.0621 & - \\
\hline 1 & {$[110000011000]$} & {$[284.482 ; 299.515 ; 252.360 ; 281.091]$} & 0.0093 & 84.93 \\
\hline 2 & [110000011000] & {$[271.482 ; 293.908 ; 305.228 ; 296.859]$} & 0.0094 & 84.89 \\
\hline
\end{tabular}

TABLE 12: Comparison between optimal solution and two alternative methods.

\begin{tabular}{lccc}
\hline Method & Position $\vec{P}$ & Friction forces $\vec{F}_{f n}[\mathrm{kN}]$ & Maximum displacement at Node 44 $[\mathrm{m}]$ \\
\hline Four optimized dampers & {$[010000111000]$} & {$[302.621 ; 304.719 ; 286.548 ; 302.900]$} & 0.0303 \\
Alternative 1 & {$[001010101000]$} & {$[302.621 ; 304.719 ; 286.548 ; 302.900]$} & 0.0562 \\
Alternative 2 & {$[11111111111]$} & 92.493 for each damper & 0.0559 \\
\hline Method & Position $\vec{P}$ & Friction forces $\vec{F}_{f n}[\mathrm{kN}]$ & Maximum interstorey drift $d_{\max }[\mathrm{m}]$ \\
\hline Four optimized dampers & {$[110000011000]$} & {$[271.482 ; 293.908 ; 305.228 ; 296.859]$} & 0.0094 \\
Alternative 1 & {$[001010101000]$} & {$[271.482 ; 293.908 ; 305.228 ; 296.859]$} & 0.0145 \\
Alternative 2 & {$[111111111111]$} & 92.493 for each damper & 0.0147 \\
\hline
\end{tabular}

storey (one damper on each predefined possible position $\left(n_{p}=12\right)$; see Figure 8$)$ with equal friction forces and whose sum is equivalent to seventy percent of structure's weight. Table 12 shows these comparisons, demonstrating optimization's results presenting a better performance.

\section{Conclusions}

As is well known, passive energy dissipation devices in structures have achieved notoriety in last years as an economic alternative in control of vibration in structures subjected to earthquakes. In the literature it is possible to find some allusive works on damper optimization, especially TMD and viscous and viscoelastic dampers in building structures. On the other hand, allusive studies on friction dampers are scarcer than other devices probably because of difficulties that a system with friction dampers presents.

The main contribution of this works is the methodology with well-known Firefly Algorithm optimization technique to carry out simultaneous optimization of friction dampers for two different objective functions: attenuate response in terms of displacement at top of structure and minimize interstorey drift for two kinds of structure: a ten-storey steel building and a six-storey concrete building. The methodology works with well-known Firefly Algorithm and for purpose of damper optimization the authors improve this algorithm through programming a second stop criterion, giving a good performance in terms of computational time.

The proposed methodology was used in computing the optimal friction forces of a given maximum number of friction dampers and their optimal placements in both of the buildings with the aim of achieving a desired reduction of structural response. It is noteworthy that methodology is flexible, allowing user to change performance function.

Concerning the computational time, the proposed methodology presents a good performance, achieving optimum design with less iterations than the maximum number of iterations set, taking around six hours. 

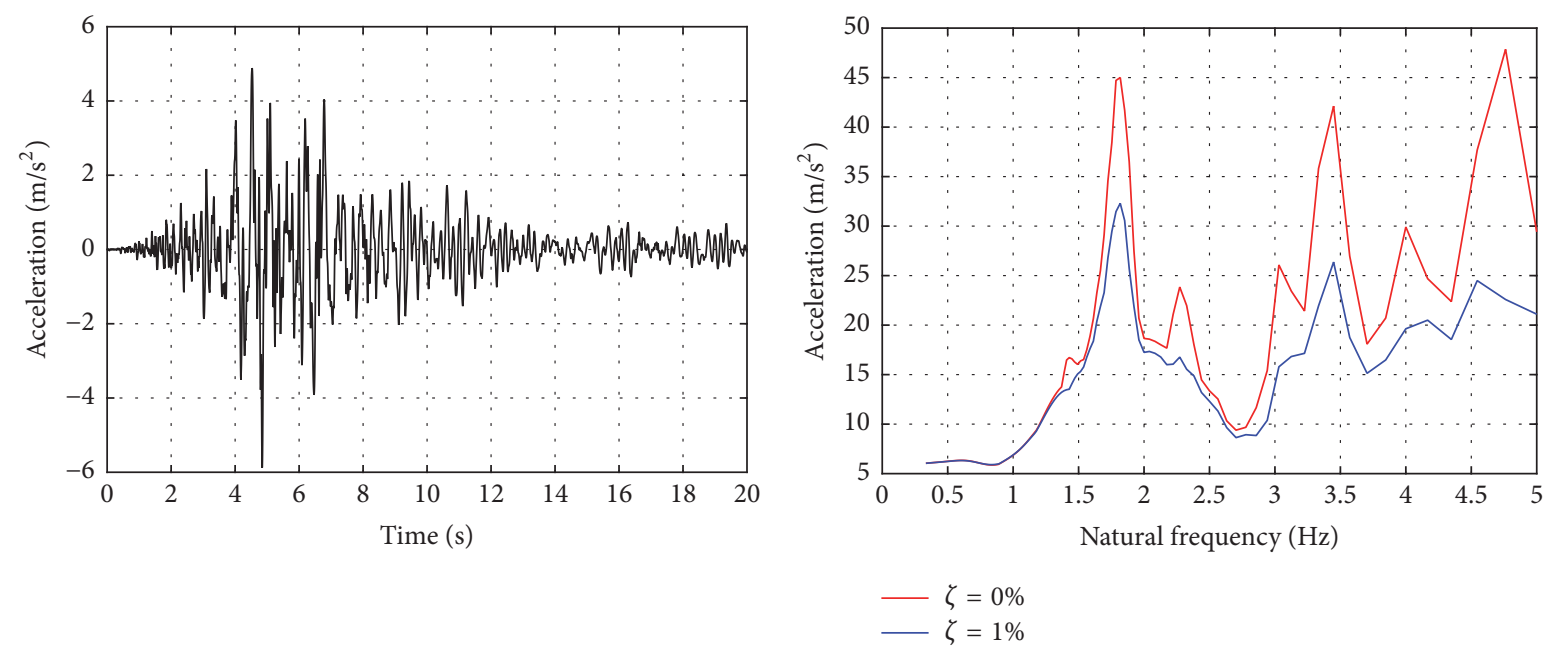

(a)

(b)
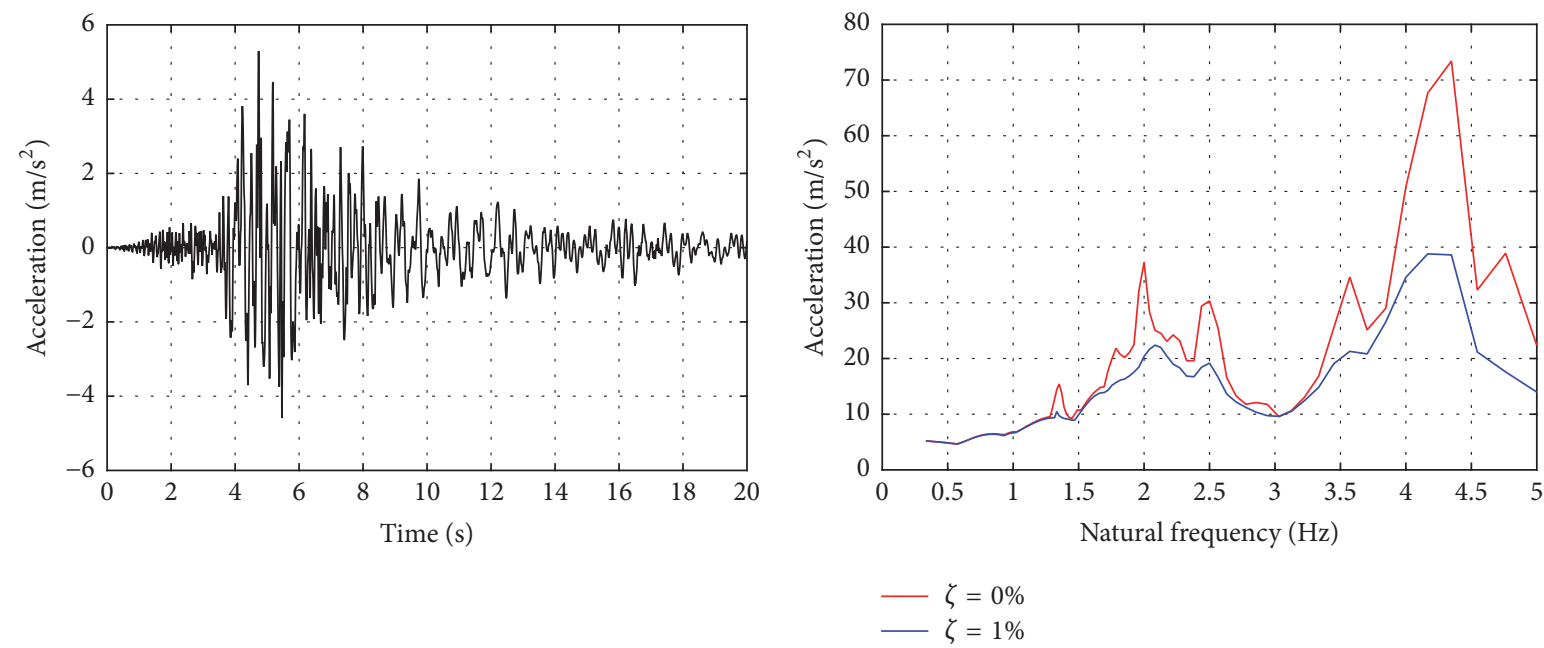

(c)

(d)
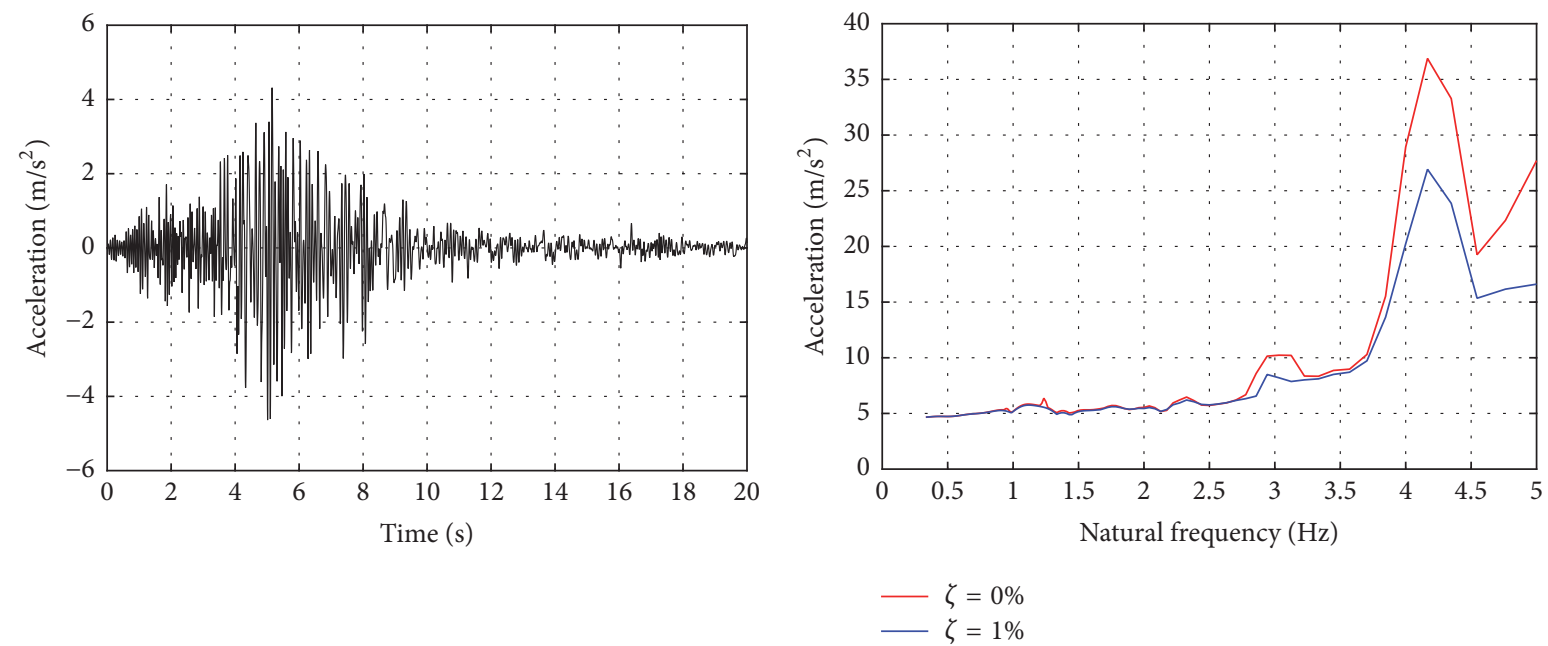

(e)

(f)

FIGURE 9: Three-component Cordoba seismic record. (a) North-South component. (b) Response spectra for North-South component. (c) East-West component. (d) Response spectra for East-West component. (e) Up component. (f) Response spectra for Up component. 


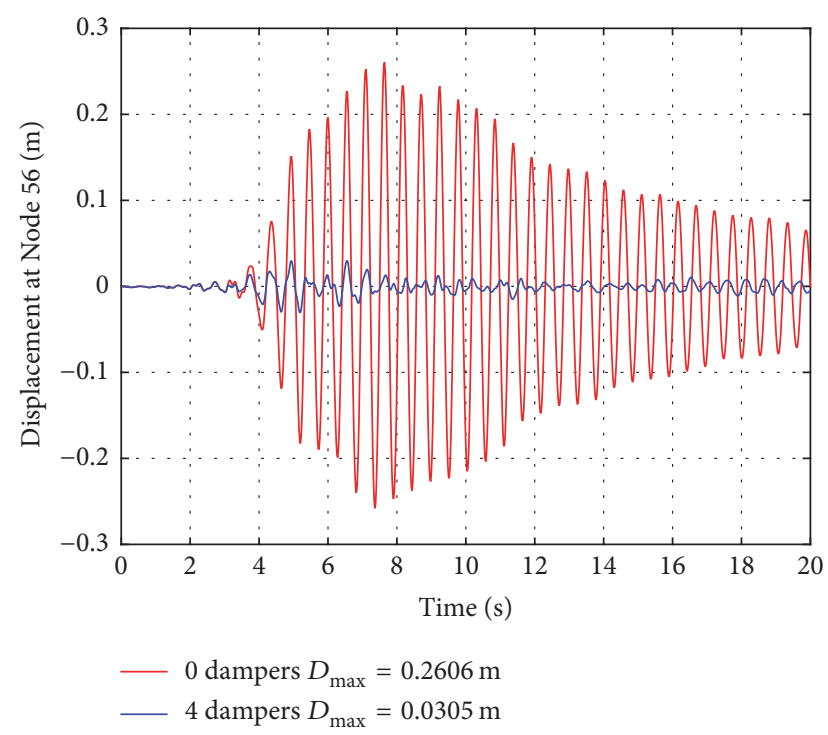

(a)

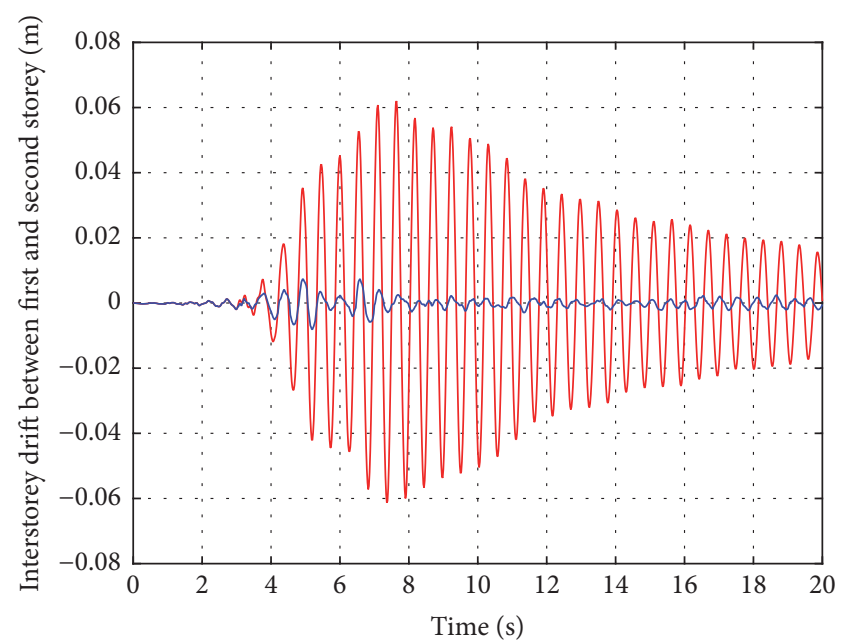

0 dampers $d_{\max }=0.0621 \mathrm{~m}$
4 dampers $d_{\max }=0.0081 \mathrm{~m}$

(c)

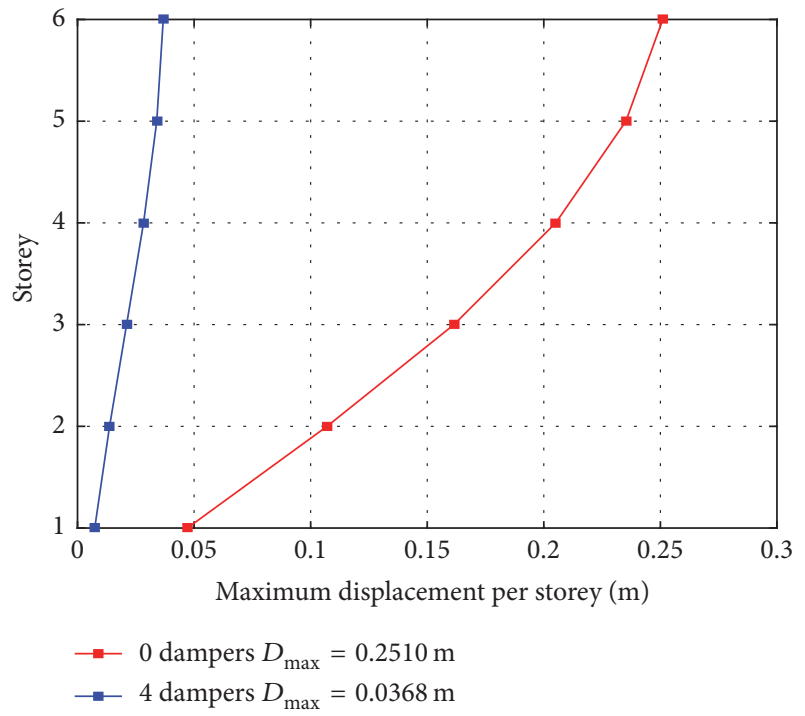

(b)

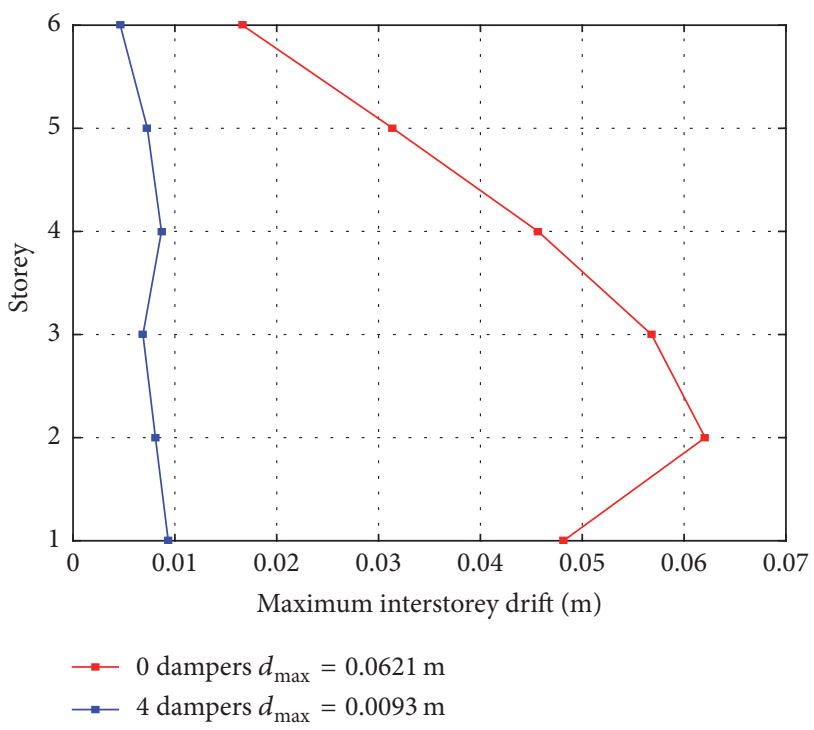

(d)

FIGURE 10: Structural response for Cordoba earthquake without control (red curve) and with four optimal friction dampers (blue curve). (a) Displacement at Node 56. (b) Envelope diagrams of maximum displacement per storey. (c) Interstorey drift between first and second storey. (d) Maximum interstorey drift per storey.

It is important to highlight that the methodologies were developed using a PC with an Intel Core i7-4700MQ 2.4 GHz CPU and 12 GB RAM; thus the computational cost is satisfactory for this sort of dynamic problem.

The proposed methodology can be recommended due to its performance as an effective tool to carry out the optimum design of friction damper for civil structures. Thus, this work shows that the design of passive devices for the vibration control as friction dampers can be accomplished in an economic and safe way, reducing costs and optimizing the resources.

\section{Conflicts of Interest}

The authors declare that they have no conflicts of interest.

\section{Acknowledgments}

The authors acknowledge the financial support of CNPq.

\section{References}

[1] T. T. Soong and G. F. Dargush, Passive Energy Dissipation Systems in Structural Engineering, Wiley, 1997. 
[2] M. M. Rocha, J. D. Riera, and L. F. F. Miguel, "O uso de amortecedores por atrito para a atenuação de vibrações em uma passarela metálica," in Proceedings of the 31st Jornadas Sul-Americanas de Engenharia Estrutural, Mendoza, Argentina, 2004.

[3] L. F. F. Miguel, R. O. Curadelli, and J. D. Riera, "Uso de amortecedores por atrito e metálicos no controle de vibrações induzidas pelo vento em torre metálica," in Proceedings of the 31st Jornadas Sul-Americanas de Engenharia Estrutural, Mendoza, Argentina, 2004.

[4] R. O. Curadelli, Riera J. D., and L. F. F. Miguel, "Seismic upgrading of existing structures through the introduction of external dampers," in Proceedings of the 1st European Conference on Earthquake Engineering and Seismology (ECEES '06), Geneva, Switzerland, 2006.

[5] L. F. F. Miguel, R. O. Curadelli, and J. D. Riera, "Structural vibration control by means of lead or friction external dampers," in Proceedings of the 4th World Conference on Structural Control and Monitoring (WCSCM '06), San Diego, Calif, USA, 2006.

[6] K.-W. Min, J.-Y. Seong, and J. Kim, "Simple design procedure of a friction damper for reducing seismic responses of a singlestory structure," Engineering Structures, vol. 32, no. 11, pp. 3539$3547,2010$.

[7] G. Carlo Marano, R. Greco, and B. Chiaia, "A comparison between different optimization criteria for tuned mass dampers design," Journal of Sound and Vibration, vol. 329, no. 23, pp. 4880-4890, 2010.

[8] E. Dehghan-Niri, S. M. Zahrai, and A. Mohtat, "Effectivenessrobustness objectives in MTMD system design: An evolutionary optimal design methodology," Structural Control and Health Monitoring, vol. 17, no. 2, pp. 218-236, 2010.

[9] Y. Arfiadi and M. N. S. Hadi, "Optimum placement and properties of tuned mass dampers using hybrid genetic algorithms," International Journal of Optimization in Civil Engineering, vol. 1, pp. 167-187, 2011.

[10] B. Farshi and A. Assadi, "Development of a chaotic nonlinear tuned mass damper for optimal vibration response," Communications in Nonlinear Science and Numerical Simulation, vol. 16, no. 11, pp. 4514-4523, 2011.

[11] Z. T. Rakicevic, A. Bogdanovic, D. Jurukovski, and P. Nawrotzki, "Effectiveness of tune mass damper in the reduction of the seismic response of the structure," Bulletin of Earthquake Engineering, vol. 10, no. 3, pp. 1049-1073, 2012.

[12] M. Mohebbi, K. Shakeri, Y. Ghanbarpour, and H. Majzoub, "Designing optimal multiple tuned mass dampers using genetic algorithms (GAs) for mitigating the seismic response of structures," Journal of Vibration and Control, vol. 19, no. 4, pp. 605625, 2013.

[13] L. F. Fadel Miguel, R. H. Lopez, and L. F. F. Miguel, "Discussion of paper: "Estimating optimum parameters of tuned mass dampers using harmony search" [Eng. Struct. 33 (9) (2011) 27162723]," Engineering Structures, vol. 54, pp. 262-264, 2013.

[14] S. P. Ontiveros-Pérez, Otimização Simultânea de posições e forças de amortecedores de vibração por atrito para controle de vibrações de estruturas [Master dissertation], PROMEC/ UFRGS, Porto Alegre, Brazil, 2014.

[15] S. P. Ontiveros-Pérez, L. F. F. Miguel, and L. F. Fadel Miguel, "Optimización simultánea de posiciones y fuerzas de amortiguadores de vibración de fricción para el control de vibraciones de estructuras," in Proceedings of the 36th Jornadas SulAmericanas de Engenharia Estrutural, Montevideo, Uruguay, 2014.
[16] S. P. Ontiveros-Pérez, L. F. F. Miguel, and L. F. Fadel Miguel, "Simultaneous optimization of passive dampers for the seismic control in structures," in Proceeedings of the International Congress of Mechanical Engineering, Rio de Janeiro, Brazil, 2015.

[17] L. F. F. Miguel, L. F. Fadel Miguel, and R. H. Lopez, "A firefly algorithm for the design of force and placement of friction dampers for control of man-induced vibrations in footbridges," Optimization and Engineering, vol. 16, no. 3, pp. 633-661, 2015.

[18] L. F. F. Miguel, L. F. F. Miguel, and R. H. Lopez, "Simultaneous optimization of force and placement of friction dampers under seismic loading," Engineering Optimization, vol. 48, no. 4, pp. 582-602, 2016.

[19] S. P. Ontiveros-Pérez, L. F. F. Miguel, and L. F. F. Miguel, "Optimization of location and forces of friction dampers," REMInternational Engineering Journal, vol. 70, no. 3, pp. 273-279, 2017.

[20] L. F. F. Miguel, R. H. Lopez, and L. F. F. Miguel, "Multimodal size, shape, and topology optimisation of truss structures using the Firefly algorithm," Advances in Engineering Software, vol. 56, pp. 23-37, 2013.

[21] S. A. Mousavi and A. K. Ghorbani-Tanha, "Optimum placement and characteristics of velocity-dependent dampers under seismic excitation," Earthquake Engineering and Engineering Vibration, vol. 11, no. 3, pp. 403-414, 2012.

[22] L. F. F. Miguel, Estudo teórico e experimental de amortecedores de vibração por atrito [Master dissertation], PPGEC/UFRGS, Porto Alegre, Brazil, 2002.

[23] N. Mostaghel and T. Davis, "Representations of Coulomb friction for dynamic analysis," Earthquake Engineering \& Structural Dynamics, vol. 26, no. 5, pp. 541-548, 1997.

[24] X. S. Yang, Nature-Inspired Metaheuristic Algorithms, Luniver Press, 2010.

[25] L. F. F. Miguel and L. F. Fadel Miguel, "Shape and size optimization of truss structures considering dynamic constraints through modern metaheuristic algorithms," Expert Systems with Applications, vol. 39, no. 10, pp. 9458-9467, 2012.

[26] A. H. Gandomi, X.-S. Yang, and A. H. Alavi, "Mixed variable structural optimization using firefly algorithm," Computers \& Structures, vol. 89, no. 23-24, pp. 2325-2336, 2011.

[27] M.-H. Horng, "Vector quantization using the firefly algorithm for image compression," Expert Systems with Applications, vol. 39, no. 1, pp. 1078-1091, 2012.

[28] M.-H. Horng and R.-J. Liou, "Multilevel minimum cross entropy threshold selection based on the firefly algorithm," Expert Systems with Applications, vol. 38, no. 12, pp. 14805-14811, 2011.

[29] X.-S. Yang, S. S. S. Hosseini, and A. H. Gandomi, "Firefly algorithm for solving non-convex economic dispatch problems with valve loading effect," Applied Soft Computing, vol. 12, no. 3, pp. 1180-1186, 2012.

[30] K. Chandrasekaran and S. P. Simon, "Network and reliability constrained unit commitment problem using binary real coded firefly algorithm," International Journal of Electrical Power \& Energy Systems, vol. 43, no. 1, pp. 921-932, 2012.

[31] M. K. Sayadi, A. Hafezalkotob, and S. G. J. Naini, "Fireflyinspired algorithm for discrete optimization problems: an application to manufacturing cell formation," Journal of Manufacturing Systems, vol. 32, no. 1, pp. 78-84, 2013.

[32] L. D. S. Coelho and V. C. Mariani, "Firefly algorithm approach based on chaotic Tinkerbell map applied to multivariable PID controller tuning," Computers \& Mathematics with Applications, vol. 64, no. 8, pp. 2371-2382, 2012. 
[33] S.-E. K. Fateen, A. Bonilla-Petriciolet, and G. P. Rangaiah, "Evaluation of Covariance Matrix Adaptation Evolution Strategy, Shuffled Complex Evolution and Firefly Algorithms for phase stability, phase equilibrium and chemical equilibrium problems," Chemical Engineering Research and Design, vol. 90, no. 12, pp. 2051-2071, 2012.

[34] A. H. Gandomi, X.-S. Yang, S. Talatahari, and A. H. Alavi, "Firefly algorithm with chaos," Communications in Nonlinear Science and Numerical Simulation, vol. 18, no. 1, pp. 89-98, 2013.

[35] I. Fister, X. Yang, J. Brest, and I. Fister Jr., "Modified firefly algorithm using quaternion representation," Expert Systems with Applications, vol. 40, no. 18, pp. 7220-7230, 2013.

[36] P. R. Srivatsava, B. Mallikarjun, and X.-S. Yang, "Optimal test sequence generation using firefly algorithm," Swarm and Evolutionary Computation, vol. 8, pp. 44-53, 2013.

[37] L. F. F. Miguel, L. F. F. Miguel, and R. H. Lopez, "Failure probability minimization of buildings through passive friction dampers," The Structural Design of Tall and Special Buildings, vol. 25, no. 17, pp. 869-885, 2016.

[38] S. S. Rao and F. F. Yap, Mechanical Vibrations, vol. 4, Prentice Hall, Upper Saddle River, NJ, USA, 2011.

[39] M. Shinozuka and C.-M. Jan, "Digital simulation of random processes and its applications," Journal of Sound and Vibration, vol. 25, no. 1, pp. 111-128, 1972.

[40] K. Kanai, "An empirical formula for the spectrum of strong earthquake motions," Bulletin of the Earthquake Research Institute, vol. 39, pp. 85-95, 1961.

[41] H. Tajimi, "A statistical method of determining the maximum response of a building structure during an earthquake," in Proceedings of the 2nd World Conference in Earthquake Engineering, pp. 781-797, Tokyo, Japan, 1960.

[42] H. Seya, M. E. Talbott, and H. H. M. Hwang, "Probabilistic seismic analysis of a steel frame structure," Probabilistic Engineering Mechanics, vol. 8, no. 2, pp. 127-136, 1993.

[43] Ministerio de Ambiente, Vivienda y Desarrollo Territorial, Reglamento Colombiano de Construcción Sismo ResistenteNSR 10, pp. 1-130, 2010. 


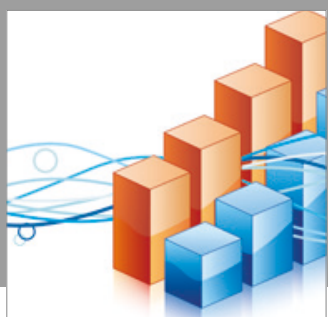

Advances in

Operations Research

vatersals

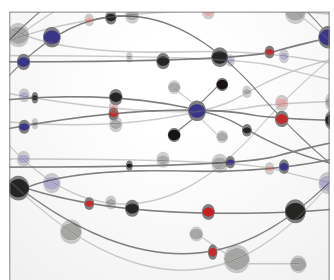

\section{The Scientific} World Journal
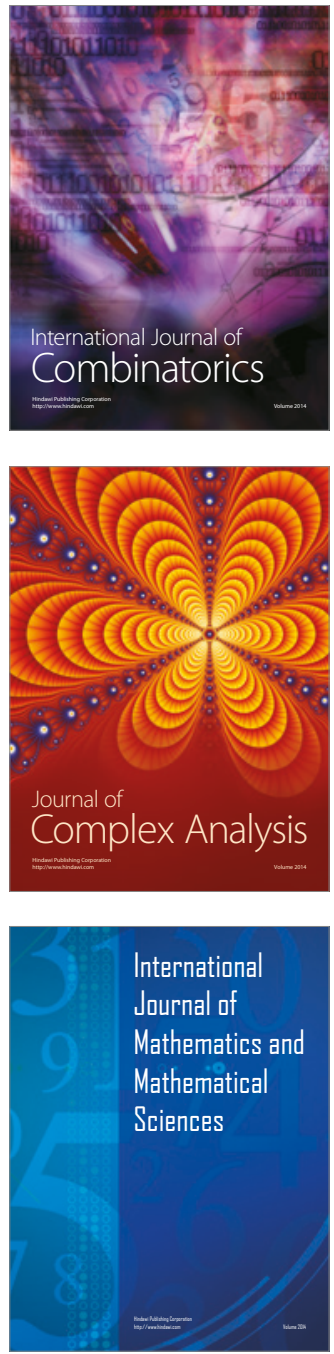
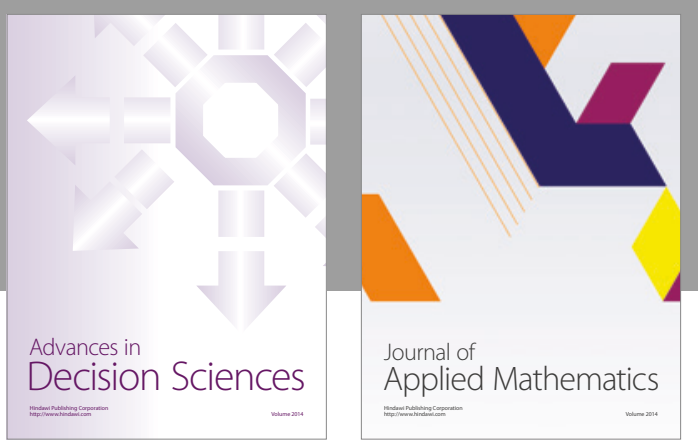

Algebra

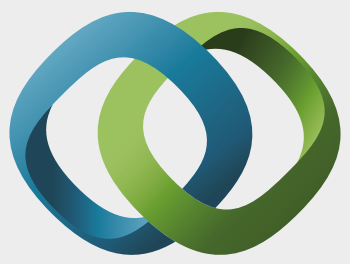

\section{Hindawi}

Submit your manuscripts at

https://www.hindawi.com
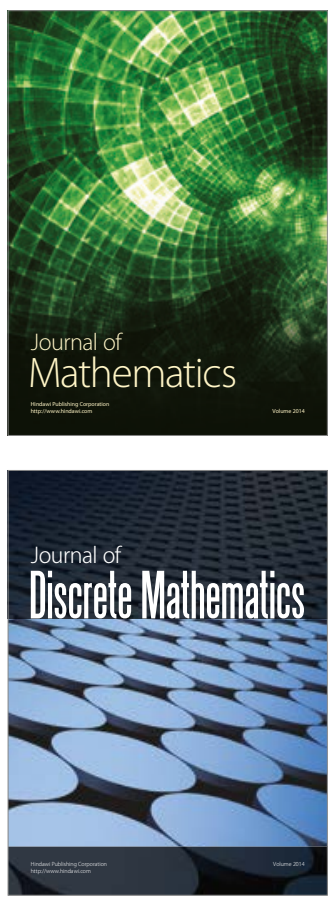

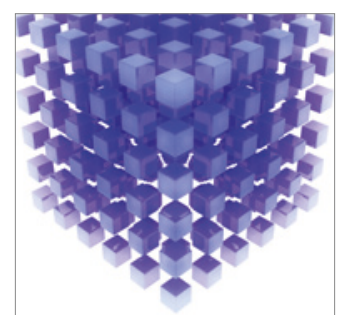

Mathematical Problems in Engineering
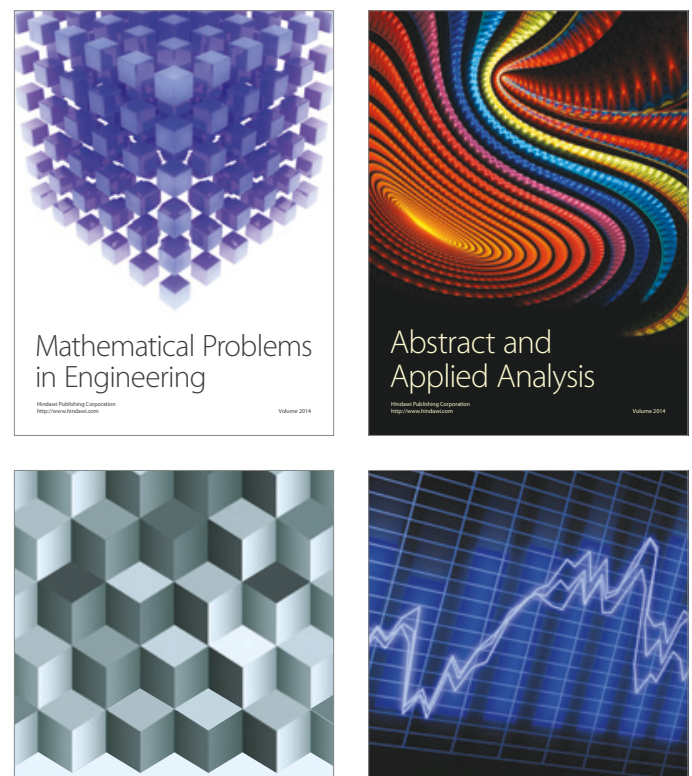

Journal of

Function Spaces

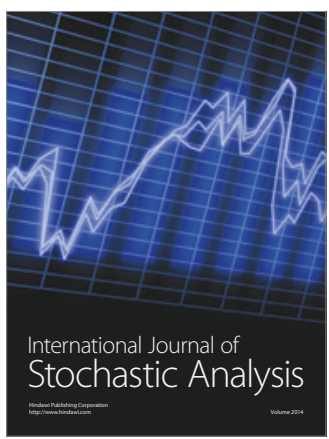

Probability and Statistics
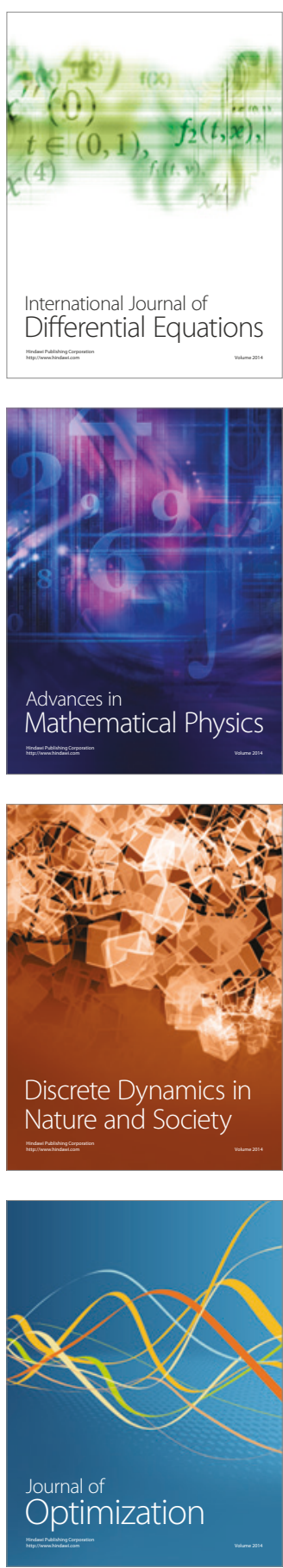